\title{
Electrospray Ionization with High-Resolution Mass Spectrometry as a Tool for
}

\section{Lignomics: Lignin Mass Spectrum Deconvolution}

Anastasia A. Andrianova, ${ }^{a}$ Thomas DiProspero, ${ }^{a, b}$ Clayton Geib, ${ }^{a}$ Irina P. Smoliakova, ${ }^{a}$ Evguenii I. Kozliak, ${ }^{a}$ Alena Kubátováa

${ }^{a}$ Department of Chemistry, University of North Dakota, 151 Cornell St., Stop 9024, Grand Forks, ND 58202, USA

${ }^{b}$ Present address: Department of Chemistry, University of North Carolina at Chapel Hill, Campus Box 3290, Chapel Hill, NC 27599, USA

Andrianova, A. A.; DiProspero, T.; Geib, C.; Smoliakova, I. P.; Kozliak, E. I.; Kubatova, A. Electrospray ionization with high-resolution mass spectrometry as a tool for lignomics: Lignin mass spectrum deconvolution. Journal of the American Society for Mass Spectrometry, 2018, 29(5), 1044-1059. https://doi.org/10.1007/s13361-018-1916-z

Address reprint requests to the corresponding author Dr. Alena Kubátová: 151 Cornell St., Stop 9024, Grand Forks, ND 58202, USA. Voice: 701-777-0348, fax: 701-777-2331. Email: alena.kubatova@UND.edu 


\section{Introduction}

Lignin constitutes the structural support of vascular plants' tissues and algae contributing up to $30 \%$ of biomass [1-4]. As a result, lignin is one of the most abundant sources of renewable carbon, a potential feedstock for renewable liquid fuel and valuable phenolic chemicals [5]. Various approaches to transform lignin into commercially beneficial substances are being investigated including extraction as well as thermal, catalytic and biological degradation [1, 3, 69].

The determination of produced low molecular weight (MW) species (<400 Da) present in the mixture of decomposition products is usually accomplished by one or two dimensional gas chromatography (GC or GC×GC) with either flame ionization (FID) or mass spectrometry (MS) detection, or by liquid chromatography with electrospray ionization (ESI) MS (LC-MS) [9]. This analysis allows for a comprehensive characterization of up to $20 \%$ of the product mass extractable by organic solvents, so-called bio-oil [9]. However, a significant non-GC-able portion of degradation products, which consists of phenolic oligomers and a so-called "coke" solid soot-like residue originating from native lignin, is only tentatively characterized [9]. Furthermore, for a comprehensive assessment of the degradation efficiency and understanding of decomposition pathways, a thorough characterization of intact lignin in the form of a native polymer is essential, yet extremely challenging.

The most common method employed for intact lignin characterization is size exclusion chromatography (SEC). Recent studies suggest Agilent PLgel columns to be the most suitable for biomass and lignin analysis in THF-based systems $[10,11]$. While this method is an excellent tool for regular polymer MW determination, its application to lignin is limited because of the lack of pertinent calibration standards. As a result, calibration is usually conducted with polystyrene 
standards, which do not match the structure of lignin [12]. Additionally, lignin's heteropolymeric nature contributes to secondary interactions of various functional groups with the column stationary phase [12-15].

Steric effects typical for rigid phenolic polymers also tend to skew SEC results [12]. To improve the accuracy of MW determination by SEC, detectors such as low-angle light scattering and multi-angle laser light scattering are frequently used [13, 16-21]. However, the determined MW values may still be skewed by the fluorescence and UV absorptivity of lignin constituents along with possible lignin macromolecule association [22].

While mass spectrometry is often the method of choice, Table 1 demonstrates the limitations of various MS approaches and unresolved issues reported for intact lignin characterization alone [14], or in combination with pyrolysis (Pyr) GC [23-33]. Pyr-GC is traditionally used to determine the type of lignin or lignocellulose, however it neither provides any MW information nor allows for a differentiation of small and large MW species [9]. The application of Pyr-GC-MS typically targets the speciation of syringol and guaiacol within lignin structural units [32].

Matrix-assisted laser desorption/ionization (MALDI) MS is currently considered the only suitable MS approach [34] for determination of MW distribution in synthetic polymers, proteins and polysaccharides [34]. However, MALDI provides only limited structural information [35-37] due to partial fragmentation, which makes it impossible to distinguish small and large molecules [35-37]. This issue could be addressed by coupling MS to LC; however, MALDI cannot be used as an online detector due to the required sample preparation procedure, which includes the analyte co-crystallization in a mixture with a matrix. Moreover, sample co-crystallization leads to undesirable association effects [38]. MALDI ionization also results in the predominant formation of single charged species, thus suppressing the ionization of high MW species and promoting the 
formation of ions featuring low $\mathrm{m} / \mathrm{z}$ ratios [36]. Additionally, the analyte MW is typically limited to the mass analyzer operation range [39]. These limitations result in a noisy lignin spectrum lacking resolved peaks, particularly on the higher end of the $\mathrm{m} / \mathrm{z}$ scale $[34,37,39,40]$.

Intact lignin has also been investigated using MS with ESI and atmospheric pressure chemical ionization (APCI). However these studies focused only on a limited $\mathrm{m} / \mathrm{z}$ range (up to $1,000 \mathrm{~m} / \mathrm{z}$ [41-47] and 1,500 m/z [42, 48-51]) aiming to evaluate lignin degradation products (Table 1) $[14,22]$. The significance of these studies was in the successful elucidation of the structural patterns and common linkages in various types of lignin, yet the MW was left undetermined [4151], as well as a potential formation of multiply charged species characteristic for ESI, which is widely used in proteomics [52], yet has not been reported to our knowledge for lignin. Several research groups utilized ESI with an extended $\mathrm{m} / \mathrm{z}$ range (up to 3,500 $\mathrm{m} / \mathrm{z}$ [53] and 7,000 $\mathrm{m} / \mathrm{z}$ [38]), however the reported spectra showed a low signal-to-noise ratio and low intensity above 1,000 m/z, possibly due to the use of ionization conditions optimized for low MW lignin model compounds. To the best of our knowledge, a thorough optimization of ionization conditions and mass analyzer parameters within an extended $\mathrm{m} / \mathrm{z}$ range aiming for a greater peak resolution and higher signalto-noise ratio has not been reported.

The intermediate products of lignin degradation, i.e., lignin mono- to oligomeric standards, appear to be suitable model compounds for understanding the ionization mechanism of intact and degraded lignin $[42,45-47]$. An extensive optimization of ESI and APCI conditions toward the analysis of mono- and several diarene lignin model compounds was reported, to our best knowledge, only in the study by Haupert et al. while utilizing a linear quadrupole ion trap MS [54]. Kosyakov et al. assessed ESI, APCI and APPI as ionization techniques focusing on specific additives for analysis of lignin and its model compounds using a quadrupole-orbitrap MS [47]. 
The limitation of APCI and APPI is their applicability only to a relatively low MW range, below $1,800 \mathrm{Da}$, and the predominant formation of singly-charged ions. In addition, APCI was shown to suffer from excessive fragmentation of lignin model compounds thus making this method inappropriate for both analysis of complex degradation mixtures $[43,54]$ and determination of intact lignin MW [44]. Thus, APPI and APCI may be preferred for studying oligomeric species and structural patterns in lignin. However, these ionization techniques cannot be applied for detection of high MW species in lignin.

Sodium hydroxide and sodium chloride have been claimed to be the most effective electrolytes while utilizing ESI, as minimal molecular ion fragmentation was observed for acidic lignin model compounds in the negative mode and for non-acidic compounds in the positive mode [54]. The ESI MS with $\mathrm{NaOH}$ method was successfully applied in combination with reversed phase LC by Owen et al., enabling a structural elucidation of some low MW components in a mixture of lignin degradation products [55]. By contrast, Kiyota et al. showed that oligomers with a MW up to 852 Da could be successfully ionized in the negative mode in the presence of 20 $\mathrm{mmol} \cdot \mathrm{L}^{-1}$ formic acid and created a do-it-yourself oligomeric database, which included mono- to tetrameric phenolic species synthesized in house [45]. Proposed in 2010 the MS-based sequencing of lignin oligomers as an identification tool allowed for coining the term "lignomics" [42, 46]. Oligomeric model compounds and isolated oligolignols (up to $650 \mathrm{~m} / \mathrm{z}$ ) were efficiently ionized with APCI and ESI in the negative mode; furthermore, the fragmentation pathways of the major bonding structures in the gas phase were elucidated $[42,46]$. All of these approaches laid the foundation for the development of an MS-based sequencing algorithm, yet they varied in ionization approaches and were limited by their focus on relatively low $\mathrm{m} / z$ values $(<900)$. Thus, 
detection of high MW species, which are essential components of lignin, remains challenging and prevents lignin MW elucidation with the currently available MS toolkit.

In this study, we have developed an MS protocol extending the lignomics toolkit through the detection of high-MW lignin components as well as low-MW phenolics. Building on previous studies [42, 45, 49, 50,54], we investigated the effect of a broader suite of electrolytes on ESI of two representative lignin-like dimers. This was followed by narrowing the range of electrolytes while assessing the ionization of eleven mono-, di- and triarene lignin model compounds featuring different oxygenated functional groups and linkages typical for lignin and then expanded the method to native lignin. This investigation led to the development of a protocol for successful ionization of high MW lignin species with a focus on the multiply charged ion formation. We also postulated and confirmed that higher MS resolution led to an improved detection of high MW species when an ion mobility (IM) feature was employed with HRMS. The determined average MW values of lignin were compared to those obtained by LDI MS and GPC. 
Table 1. Comprehensive Overview of the MS Approaches Employed for the Analysis of Intact Lignin and High MW Standards

\begin{tabular}{|c|c|c|c|c|c|c|}
\hline $\begin{array}{c}\text { Ionization } \\
\text { Mode }\end{array}$ & Mass Analyzer & Analyte & Solvent & $\begin{array}{c}\text { Electrolyte/ } \\
\text { MALDI Matrix }\end{array}$ & $\begin{array}{c}\text { MW or } m / z \\
\text { Range Detected }\end{array}$ & Ref \\
\hline \multicolumn{7}{|c|}{ APPI } \\
\hline- & Q-orbitrap & Dioxane lignin & $\begin{array}{l}\text { Acetone-water mixture } \\
(9: 1)\end{array}$ & $0.1 \% \mathrm{NH}_{4} \mathrm{OH}$ & $300-1800 \mathrm{~m} / \mathrm{z}$ & {$[47]$} \\
\hline+ & HR Q-TOF-MS & Wheat straw lignin & Dioxane $(100 \%)$ or & $\mathrm{NR}^{\mathrm{a}}$ & Positive mode: & {$[41]$} \\
\hline- & HR Q-TOF-MS & Wheat straw lignin & Dioxane/MeOH/CHCl 3 & & $300-1,120 \mathrm{~m} / \mathrm{z}$ & \\
\hline$+1-$ & HR Q-TOF-MS/MS & Oligomeric species in lignin & $(1: 1: 1)$ & & $\begin{array}{l}\text { Negative mode: } \\
200-700 \mathrm{~m} / \mathrm{z}\end{array}$ & \\
\hline \multicolumn{7}{|c|}{ APCI } \\
\hline- & Q-orbitrap & Dioxane lignin & $\begin{array}{l}\text { Acetone-water mixture } \\
(9: 1)\end{array}$ & $0.1 \% \mathrm{NH}_{4} \mathrm{OH}$ & $300-1800 \mathrm{~m} / \mathrm{z}$ & [47] \\
\hline- & Ion trap & Synthesized oligomeric standards & $\mathrm{H}_{2} \mathrm{O} / \mathrm{MeOH}(50: 50)$ & $0.1 \%$ acetate & $100-1,000 \mathrm{~m} / \mathrm{z}$ & {$[42]$} \\
\hline- & Single quadrupole & $\begin{array}{l}\text { Lignin partially depolymerized } \\
\text { under acetic conditions }\end{array}$ & $\mathrm{H}_{2} \mathrm{O} / \mathrm{MeOH}$ & NR & $150-650 \mathrm{~m} / \mathrm{z}$ & {$[43]$} \\
\hline$+/-$ & $\begin{array}{l}\text { Quadrupole- } \\
\text { hexapole-- } \\
\text { quadrupole }\end{array}$ & $\begin{array}{l}\text { Wheat straw intact and acetylated } \\
\text { lignin }\end{array}$ & $\mathrm{CHCl}_{3} / \mathrm{MeOH}(2: 1)$ & $\begin{array}{l}\text { A mixture of formic and } \\
\text { acetic acid }\end{array}$ & $100-550 \mathrm{~m} / \mathrm{z}$ & {$[44]$} \\
\hline
\end{tabular}




\begin{tabular}{|c|c|c|c|c|c|}
\hline Ionization & Mass Analyzer & Analyte & Solvent & Electrolyte/ & MW or $m / z$ \\
\hline Mode & & & & MALDI Matrix & Range Detected \\
\hline
\end{tabular}

ESI

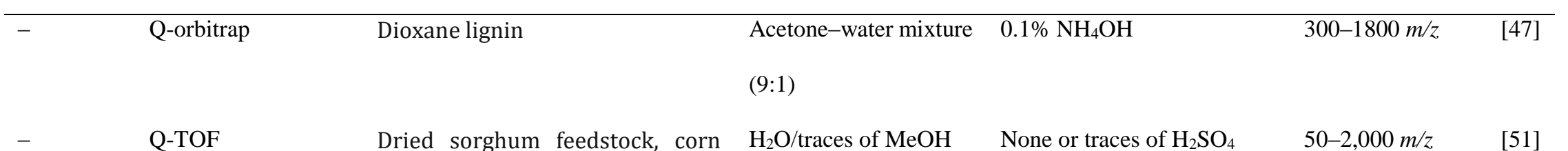

Q-TOF

stover hydrolysate, xylobiose and

xylotetraose

$+\quad$ Linear trap

Bagasse lignin (100-100,000 g. $\mathrm{mol}^{-}$

quadrupole -

${ }^{1}$ with a maximum at $2 \cdot 10^{3} \mathrm{~g} \cdot \mathrm{mol}^{-1}$

Fourier transform

according to GPC);

hybrid linear trap/7- steam explosion lignin

T Fourier transform

- ion cyclotron

resonance MS

Magnetic sector Spruce and eucalyptus dioxane $\mathrm{MeOH} / \mathrm{H}_{2} \mathrm{O}(1: 1) / 2.5 \%$

Q-TOF (unresolved at

higher $m / z$ )

$50-1,500 \mathrm{~m} / \mathrm{z}$
$0.25 \% \mathrm{NH}_{4} \mathrm{OH}^{\mathrm{b}}$

$(1: 1) / 0.25 \% \mathrm{NH}_{3}$ 


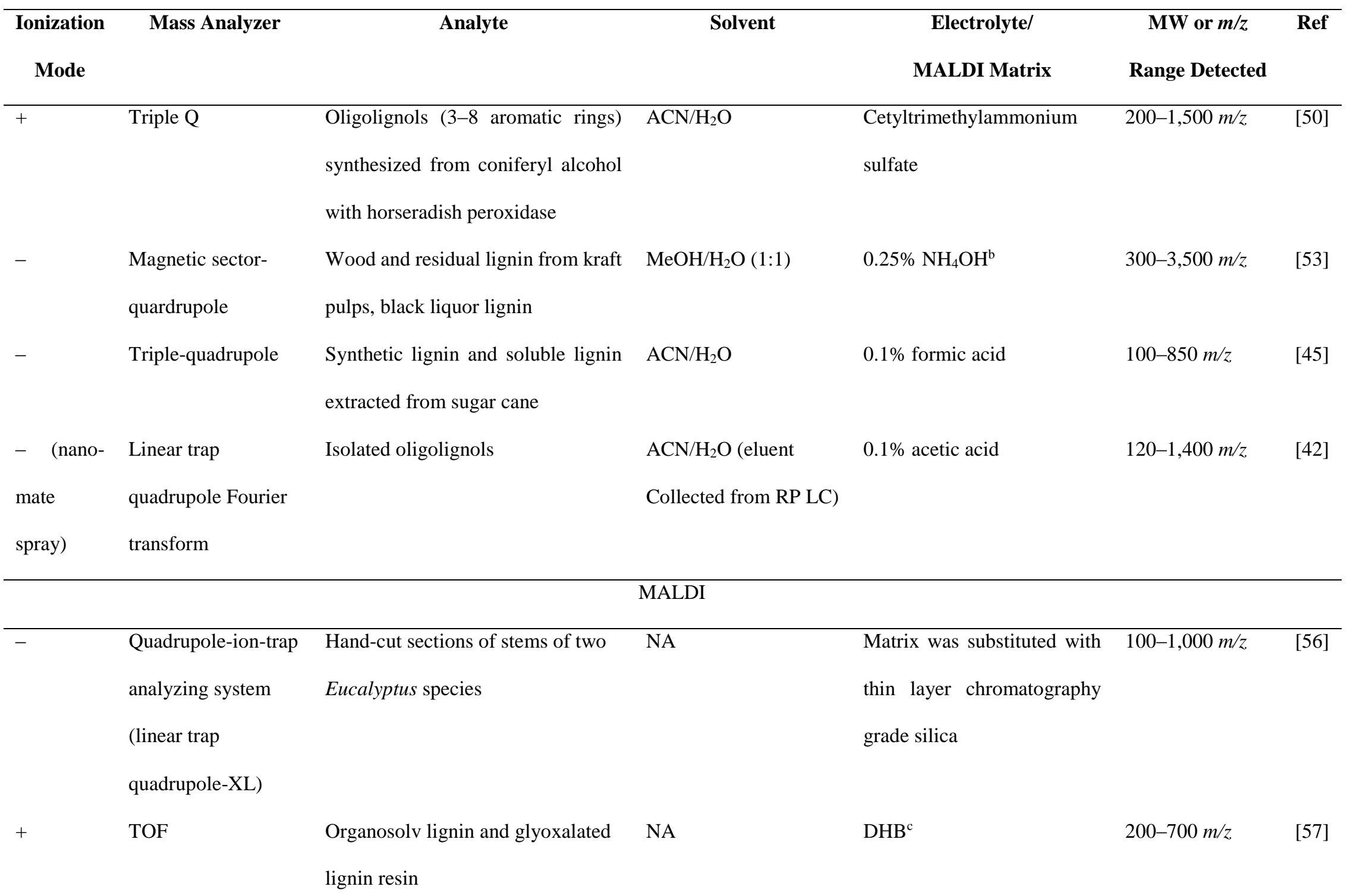




\begin{tabular}{|c|c|c|c|c|c|c|}
\hline $\begin{array}{c}\text { Ionization } \\
\text { Mode }\end{array}$ & Mass Analyzer & Analyte & Solvent & $\begin{array}{c}\text { Electrolyte/ } \\
\text { MALDI Matrix }\end{array}$ & $\begin{array}{c}\text { MW or } m / z \\
\text { Range Detected }\end{array}$ & Ref \\
\hline+ & TOF & $\begin{array}{l}\text { Bagasse lignin }\left(100-100,000 \mathrm{~g} \cdot \mathrm{mol}^{-}\right. \\
{ }^{1} \text { with a maximum at } 2 \cdot 10^{3} \mathrm{~g} \cdot \mathrm{mol}^{-1} \\
\text { according to GPC); } \\
\text { steam explosion lignin }\end{array}$ & NA & DHB & $\begin{array}{l}\text { Mass distribution } \\
\text { with a maximum } \\
\text { around } m / z 360 \text {; } \\
\text { no signal above } \\
2000 \mathrm{~m} / \mathrm{z}\end{array}$ & {$[48]$} \\
\hline$+1-$ & TOF & $\begin{array}{l}\text { Lignin fractions extracted from } \\
\text { Miscanthus } x \text { giganteus under } \\
\text { alkali or acid conditions }\end{array}$ & NA & $\mathrm{CHCA}^{\mathrm{d} / \alpha \text {-cyclodextrin }}$ & $100-800 \mathrm{Da}$ & [35] \\
\hline$+/-$ & TOF & $\begin{array}{l}\text { Ssoftwood kraft lignin, mixed } \\
\text { hardwood organosolv lignin, acid } \\
\text { hydrolysis lignin from bagasse, and } \\
\text { steam explosion lignin from aspen } \\
\text { (acetylated sample) }\end{array}$ & NA & $\begin{array}{l}\text { DHB or all-trans-retinoic } \\
\text { acid }\end{array}$ & $\begin{array}{l}50-14,000 \mathrm{~m} / \mathrm{z} \\
\text { (unresolved at } \\
\text { higher } \mathrm{m} / \mathrm{z} \text { ); } 50- \\
14,000 \mathrm{Da} \\
\text { (singly charged } \\
\text { ions are almost } \\
\text { exclusively } \\
\text { generated) }\end{array}$ & [39] \\
\hline
\end{tabular}




\begin{tabular}{|c|c|c|c|c|c|c|}
\hline $\begin{array}{c}\text { Ionization } \\
\text { Mode }\end{array}$ & Mass Analyzer & Analyte & Solvent & $\begin{array}{c}\text { Electrolyte/ } \\
\text { MALDI Matrix }\end{array}$ & $\begin{array}{c}\text { MW or } m / z \\
\text { Range Detected }\end{array}$ & Ref \\
\hline & & $\begin{array}{l}\text { obtained by enzymic } \\
\text { polymerization of coniferyl alcohol }\end{array}$ & & $\begin{array}{lll}\text { Sinapinic acid } & \text { was } \\
\text { preferred.) } & & \end{array}$ & 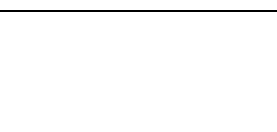 & \\
\hline$+/-$ & $\begin{array}{l}\text { Quadrupole ion trap } \\
\text { TOF (QIT-TOF) }\end{array}$ & Dioxane lignin & NA & $\begin{array}{l}N \text {-tert-butyl- } N \text {-isopropyl- } N \text { - } \\
\text { methylammonium } \alpha \text {-cyano- } \\
\text { 4-hydroxycinnamate ionic } \\
\text { liquid or no matrix. The } \\
\text { latter provided poor spectral } \\
\text { data. }\end{array}$ & $\begin{array}{l}50-2,000 \mathrm{Da} \\
\text { (unresolved) and } \\
2000-6000 \mathrm{Da} \\
\text { (unresolved) }\end{array}$ & [34] \\
\hline+ & TOF & $\begin{array}{l}\text { Milled wood lignin and synthetic } \\
\text { lignin (polymerisation of coniferyl } \\
\text { alcohol with peroxidase) }\end{array}$ & NA & DHB & $400-2,600 \mathrm{Da}$ & [36] \\
\hline+ & TOF & $\begin{array}{l}\text { Pyrolytic lignin and its SEC } \\
\text { fractions }\end{array}$ & NA & DHB or no matrix & $\begin{array}{l}50-4,000 \mathrm{Da} \\
\text { (unresolved) }\end{array}$ & [40] \\
\hline NA & TOF & $\begin{array}{l}\text { Soda hardwood lignin (Eucalyptus) } \\
\text { and softwood kraft lignin }\end{array}$ & NA & DHB & $70-700 \mathrm{Da}$ & [59] \\
\hline+ & TOF & $\begin{array}{l}\text { Native and degraded birch wood } \\
\text { lignin }\end{array}$ & NA & DHB & $1,000-2,000 \mathrm{~m} / \mathrm{z}$ & [37] \\
\hline
\end{tabular}




\begin{tabular}{|c|c|c|c|c|c|c|}
\hline $\begin{array}{c}\text { Ionization } \\
\text { Mode }\end{array}$ & Mass Analyzer & Analyte & Solvent & $\begin{array}{c}\text { Electrolyte/ } \\
\text { MALDI Matrix }\end{array}$ & $\begin{array}{c}\text { MW or } m / z \\
\text { Range Detected }\end{array}$ & Ref \\
\hline+ & TOF & $\begin{array}{l}\text { Milled wood lignin, birch kraft } \\
\text { lignin, isolated }\end{array}$ & $\begin{array}{l}\text { DCM/EtOH (2:1) or } \\
\text { DMSO prior to } \\
\text { deposition on silver } \\
\text { disk }\end{array}$ & None & $10-1,200 \mathrm{~m} / \mathrm{z}$ & {$[60]$} \\
\hline
\end{tabular}

${ }^{\mathrm{a}} \mathrm{NR}$ denotes not reported

${ }^{\mathrm{b}}$ The w/v concentration was provided in respect to $\mathrm{NH}_{3}$

${ }^{c}$ DHB stands for 2,5-dihydroxybenzoic acid

${ }^{\mathrm{d}}$ CHCA stands for $\alpha$-cyano-4-hydroxycinnamic acid 


\section{Experimental}

\section{Materials and reagents}

All standards used in this study as lignin model compounds are listed in Table 2, along with their acronyms, while details are provided in Supplementary Table 1. Alkali lignin (CAS Number: 8068-05-1), cesium iodide (99.999\%), ammonium acetate ( $\geq 99 \%$ ), sodium iodide (99.999\%), lithium chloride (99.999\%), lithium hydroxide (99.998\%) and sodium hydroxide ( $\geq 98 \%)$ were purchased from Sigma-Aldrich (St. Louis, Mo, USA). Ammonium hydroxide, trifluoroacetic, acetic and formic acids (puriss p.a., eluent additive for LC-MS) were obtained from Fluka.

MALDI matrices, i.e., 2-(4'-hydroxybenzeneazo)benzoic acid (HABA, $\geq 99.5 \%)$ and $\alpha$ cyano-4-hydroxycinnamic acid (CHCA, $\geq 99 \%$ ), were purchased from Sigma-Aldrich. HPLC-MS grade water, acetonitrile (ACN), unstabilized tetrahydrofuran (THF) and methanol (MeOH) were obtained from Fisher Scientific (Fair Lawn, NJ, USA). All chemicals were used as received, without further purification. Deionized water was obtained using a Direct-Q® 3 system, Millipore, Billerica, MA, USA. 
Table 2. List of Lignin Model Compounds Used in This Study

\begin{tabular}{|c|c|c|c|c|c|}
\hline Compounds & Acronym & $\begin{array}{l}\text { Characteristic } \\
\text { functionality }^{\mathrm{a}}\end{array}$ & $\begin{array}{c}\text { MW } \\
\left(\mathrm{g} \cdot \mathrm{mol}^{-1}\right)\end{array}$ & Supplier/Synthesized & Purity \\
\hline Vanillin & $\mathrm{V}$ & Carbonyl & 152.15 & Sigma-Aldrich $^{\mathrm{b}}$ & $99 \%$ \\
\hline Guaiacol & G & - & 124.24 & Sigma-Aldrich & $98 \%$ \\
\hline Eugenol & E & Alkenyl & 164.20 & Acros Organics ${ }^{\mathrm{c}}$ & $99 \%$ \\
\hline Vanillic acid & VA & Carboxyl & 168.15 & Fluka $^{\mathrm{d}}$ & $97 \%$ \\
\hline Syringol & S & Methoxy & 154.16 & Acros Organics & $99 \%$ \\
\hline Homovanillyl alcohol & HA & Aliphatic hydroxyl & 168.19 & Sigma-Aldrich & $99 \%$ \\
\hline Veratrole & VER & - & 138.16 & Sigma-Aldrich & $99 \%$ \\
\hline Syringaldehyde & SA & Carbonyl & 182.17 & Sigma-Aldrich & $98 \%$ \\
\hline Pinoresinol & $\mathrm{P} 2$ & Hydroxyl, methoxy & 358.38 & Sigma-Aldrich & $\geq 95 \%$ \\
\hline Guaiacylglycerol- $\beta$-guaiacyl ether & $\mathrm{G}-\beta-2$ & $\begin{array}{c}\text { Aliphatic hydroxyl, } \\
\text { methoxy, } \beta \text {-O-4 }\end{array}$ & 320.34 & In-house synthesis [61]. & $\geq 95 \%$ \\
\hline 1,2-Dimethoxy-4-[(2-methoxyphenoxy)methyl]benzene & ET2 & Methoxy, ether dimer & 274.12 & In-house synthesis [62]. & $\geq 95 \%$ \\
\hline 4-(1-Hydroxyethyl)-2-methoxyphenyl benzoate & ALC2 & $\begin{array}{c}\text { Aliphatic hydroxyl } \\
\text { dimer, ester }\end{array}$ & 272.1 & In-house synthesis [62]. & $\geq 95 \%$ \\
\hline 4-Formyl-2-methoxyphenyl benzoate & EST2 & Carbonyl, ester dimer & 256.07 & In-house synthesis [62]. & $\geq 95 \%$ \\
\hline (E)-4,4'-(Ethene-1,2-diyl)bis(2-methoxyphenol) & ALK2 & $\begin{array}{c}\text { Hydroxyl, methoxy, } \\
\text { alkene dimer }\end{array}$ & 272.10 & In-house synthesis [59]. & $\geq 95 \%$ \\
\hline
\end{tabular}


${ }^{a}$ Functional groups and linkages (for oligomers) featured in the studied methoxyphenols compared to guaiacol

${ }^{\mathrm{b}}$ Sigma-Aldrich (St. Louis, MO, USA)

${ }^{c}$ Acros Organics (Morris Plains, NJ, USA)

${ }^{\mathrm{d}}$ Fluka (Steinheim, Germany) 
Several dimeric lignin model compounds, i.e., D2V [63, 65], G- $\beta$-2 [61], ET2 [62], EST2 [62], ALC2 [62], ALK2 [62], and ET3 [62] featuring different functional groups and linkages (Table 2) were synthesized according to the procedures published earlier, with an addition of column chromatography and recrystallization purification steps. A detailed description of the syntheses can be found under Supplementary Material. These compounds were characterized by ${ }^{1} \mathrm{H}$ NMR, GC-MS and direct infusion ESI HR TOF MS.

Stock solutions of lignin mono-, di-, and trimeric standards were prepared in 50\% $\mathrm{MeOH} /$ water with a final concentration of $100 \mathrm{ppm} \mathrm{w} / \mathrm{v}$. For intact lignin analysis, it was essential to dissolve the polymer while avoiding the use of aggressive solvents such as dimethyl sulfoxide or $N, N$-dimethylformamide. We have shown that alkali lignin may be completely dissolved in ACN-water (1:1) or THF-water (1:1) mixtures, with concentrations up to $10,000 \mathrm{ppm}$ and $50,000 \mathrm{ppm}(\mathrm{w} / \mathrm{v})$, respectively. It is of note that neither pure organic solvents (ACN, THF) nor water dissolved any amounts of lignin to form a true solution. For direct infusion analysis of lignin, alkali lignin was completely dissolved in either water/ACN (1:1) or water/THF (1:1) at a final concentration of 100 or $1000 \mathrm{ppm}$, respectively. The solutions were diluted to a final lignin concentration of 80 or $90 \mathrm{ppm}$ prior to the analysis. Neither of the utilized electrolytes caused lignin precipitation. All samples and stock solutions were stored in a refrigerator at $4{ }^{\circ} \mathrm{C}$ prior to analysis.

To address the solubility issue in THF, the effect of acetylation was evaluated [66]. Acetylation of lignin samples was performed by a conventional method [67]. In brief, about $50 \mathrm{mg}$ of the sample was completely dissolved in $500 \mu \mathrm{L}$ of dry pyridine and reacted with $500 \mu \mathrm{L}$ of acetic anhydride. The reaction mixture was stirred for $12 \mathrm{~h}$ at room temperature. Then, $200 \mu \mathrm{L}$ of methanol was added to the reaction mixture to terminate the reaction. Solvents were evaporated 
under a stream of nitrogen and the residue was dried in a vacuum oven at $30{ }^{\circ} \mathrm{C}$ overnight. Acetylated lignin was completely dissolved in $5.5 \mathrm{~mL}$ of THF resulting in a $10,000 \mathrm{ppm} \mathrm{w} / \mathrm{v}$ solution, which was further diluted with water/ACN (1:1) or water/THF (1:1) mixtures for the ESI TOF MS analysis.

\section{MS Analysis: Ionization}

An Agilent 6210 ESI HR TOF-MS system was used throughout the study for method development and parameter optimization. An initial optimization of MS conditions included selection of the ionization polarity, electrospray (e.g., capillary) and collision-induced dissociation (e.g., fragmentor) potentials, nebulization temperature, nebulizing gas flow rate and nebulization pressure. Samples were introduced via a direct infusion with a syringe pump at a flow of $5 \mu \mathrm{L} \cdot \mathrm{min}^{-}$

1 for the initial optimization. ESI potentials were optimized between 2000 and $5000 \mathrm{~V}$. Nebulization pressure, gas flow and vaporizer temperature were varied between $18-40 \mathrm{psi}, 4-12$ $\mathrm{L} \cdot \min ^{-1}$, and $250-400^{\circ} \mathrm{C}$, respectively. The full range of electrolytes specified in the Materials and Reagents section was evaluated. In the experiments involving THF, all PEEK tubings were replaced with stainless steel.

To optimize the electrolyte concentration, a flow injection analysis (FIA) was performed employing an Agilent 1100 Series HPLC. An aliquot $(20 \mu \mathrm{L})$ of the prepared solution was injected into a mobile phase consisting of $50 \% \mathrm{ACN}$ or $\mathrm{MeOH}$ in water at a flow rate of $0.2-1.0 \mathrm{~mL} \cdot \mathrm{min}^{-1}$ and delivered directly to the TOF-MS system (no LC column was installed). In this study, we optimized the electrolyte concentration in the mobile phase by doping it only into the sample as we did previously in our work [68]. We experimentally confirmed that the final electrolyte 
concentration in the mobile phase after the injection of an electrolyte-doped sample remained the same (Supplementary Table 2).

The TOF-MS system was calibrated with an ESI $(50-3500 \mathrm{~m} / \mathrm{z})$ tuning mixture purchased from Agilent. For higher $m / z$ measurements (i.e., analysis of intact lignin in a range of 150$10,000 \mathrm{~m} / \mathrm{z}$ ), the calibration was performed in the positive mode while using $\left[(\mathrm{CsI})_{\mathrm{n}}+\mathrm{Cs}\right]^{+}$clusters formed by an introduction of cesium iodide $\left[30 \mathrm{mmol} \cdot \mathrm{L}^{-1}\right.$ solution in ACN/water $\left.1: 1(\mathrm{v} / \mathrm{v})\right]$ via direct infusion at a flow rate of $5 \mu \mathrm{L} \cdot \mathrm{min}^{-1}$ (Supplementary Fig. 1). Agilent $6560 \mathrm{IM}$ Q-TOF system equipped with an ESI source was used to acquire IM mass spectra under the optimized conditions determined with 6210 TOF MS system.

A MALDI SYNAPT G2-Si Q-TOF MS System (Waters, Milford, MA, USA) with CryLaS FTS355-Q laser (a repetition rate of $2.5 \mathrm{kHz}$, wavelength $355 \mathrm{~nm}$ ) was employed to acquire MALDI MS spectra in the range $50-8000 \mathrm{~m} / \mathrm{z}$. The system was manually calibrated with red phosphorus, and the experiments were performed in the positive resolution mode $(20,000)$. The laser energy was set to 350 arbitrary intensity units. Typically, HABA [36, 37, 39, 40, 48, 57-59], CHCA [34, 35], retinoic [39] or sinapinic [58] acids were used as matrices for lignin analysis. Contradicting results were reported on the analysis with no matrix used (LDI); some studies claim successful ionization $[40,56]$ while the others report it to be ineffective [34]. In this study, we evaluated lignin ionization with $\mathrm{CHCA}$ and $\mathrm{HABA}$ used as matrices and without any matrix. The best ionization effectiveness was achieved when no matrix was used.

\section{MS Characteristics and Data Processing}

The 6210 HR TOF-MS system with a mass resolution of $>13,000$ (at $m / z, 2,722$ ) and mass accuracy <2 ppm ( $\mathrm{m} / \mathrm{z}$ 609.2807) was utilized. A 6560 IM Q-TOF MS system used for IM mass 
imaging had a resolution of $>42,000$ (at $\mathrm{m} / \mathrm{z} 2,722$ ) and mass accuracy $<2 \mathrm{ppm}$. The resolving power of SYNAPT G2-Si MS system was 50,000 and the mass accuracy was under $1 \mathrm{ppm}$.

Mass Hunter software packages, B.02.00 and B.07.00, were used for data processing. The spectra of intact lignin recorded in the positive mode, which included multiply charged ions, were deconvoluted using a built-in tool utilizing an unbiased isotope model with a peak spacing tolerance of $0.0025 \mathrm{~m} / \mathrm{z}$. The maximal assigned charge state was not limited. Both hydrogen and sodium were considered as the charge carriers. The peaks selected for deconvolution were filtered based on their absolute height ( $\geq 100$ counts) and the relative height of the largest peak, which was set to $\geq 0.1 \%$ of the largest peak unless otherwise stated. The maximum number of peaks was not specified.

Equation 1 was used for the MW $(M)$ calculation of the multiply charged species:

$$
\frac{m}{z} \cdot z-\left[\left(\text { atomic mass of charge carrier }\left({ }^{1} \mathrm{H} \text { or }{ }^{23} \mathrm{Na}\right)-\text { electron rest mass }\right) \cdot z\right]=M, D a
$$

An open source alternative software for mass spectrometric data analysis mMass Data Miner [69] was used for MALDI data processing.

To qualitatively assess the MW distribution of lignin utilizing the MS data, we applied an approach used in our previous work for MALDI MS data interpretation [11]. To calculate the number average $\left(M_{n}\right)$, weight average $\left(M_{w}\right)$ and z-average $\left(M_{z}\right)$ MW of lignin samples, equations $2-4$, where $I_{i}$ is the absolute abundance of the deconvoluted species of a given MW $\left(M_{i}\right)$, were used.

$$
\begin{aligned}
& M_{n}=\frac{\sum I_{i} M_{i}}{\sum I_{i}} \\
& M_{w}=\frac{\sum I_{i} M_{i}^{2}}{\sum I_{i} M_{i}} \\
& M_{z}=\frac{\sum I_{i} M_{i}^{3}}{\sum I_{i} M_{i}^{2}}
\end{aligned}
$$




\section{Results and Discussion}

\section{Electrolyte Screening: Effect on the Representative Model Compounds}

We optimized the ESI TOF MS ionization targeting a broad range of electrolytes using two representative dimers as model compounds (Fig. 1). Two dimers, G- $\beta-2$ and ET2, were selected for this initial screening, the former featuring both aromatic and aliphatic hydroxyl groups, while the latter does not have any hydroxyl groups. Both of these standards exhibited the most efficient ionization while forming sodium adducts in the positive mode in the presence of formic or acetic acids at $\leq 10 \mathrm{mmol} \cdot \mathrm{L}^{-1}$ concentration (Fig. 1 ).

A preferable ionization of ET2 in the positive ESI mode was expected, due to the lack of hydroxyl groups in its structure. For the hydroxylated compound G- $\beta-2$, contrary to expectations, the ionization efficiency improved in the positive ESI mode resulting in an abundant sodium adduct ion (Fig. 1a). The formation of sodium adduct ions even when sodium was not purposely added to the samples is known to occur because of traces of sodium leaching from glassware [71].

An effective ionization was also observed with no electrolyte present (Fig. 1a), the feature frequently observed in ESI TOF MS [72]. However, these conditions were deemed to be nonoptimal as the lack of a buffer could result in $\mathrm{pH}$ instability and consequently cause the dependence of ionization on the sample composition and, as a result, irreproducible data [72]. 
a)

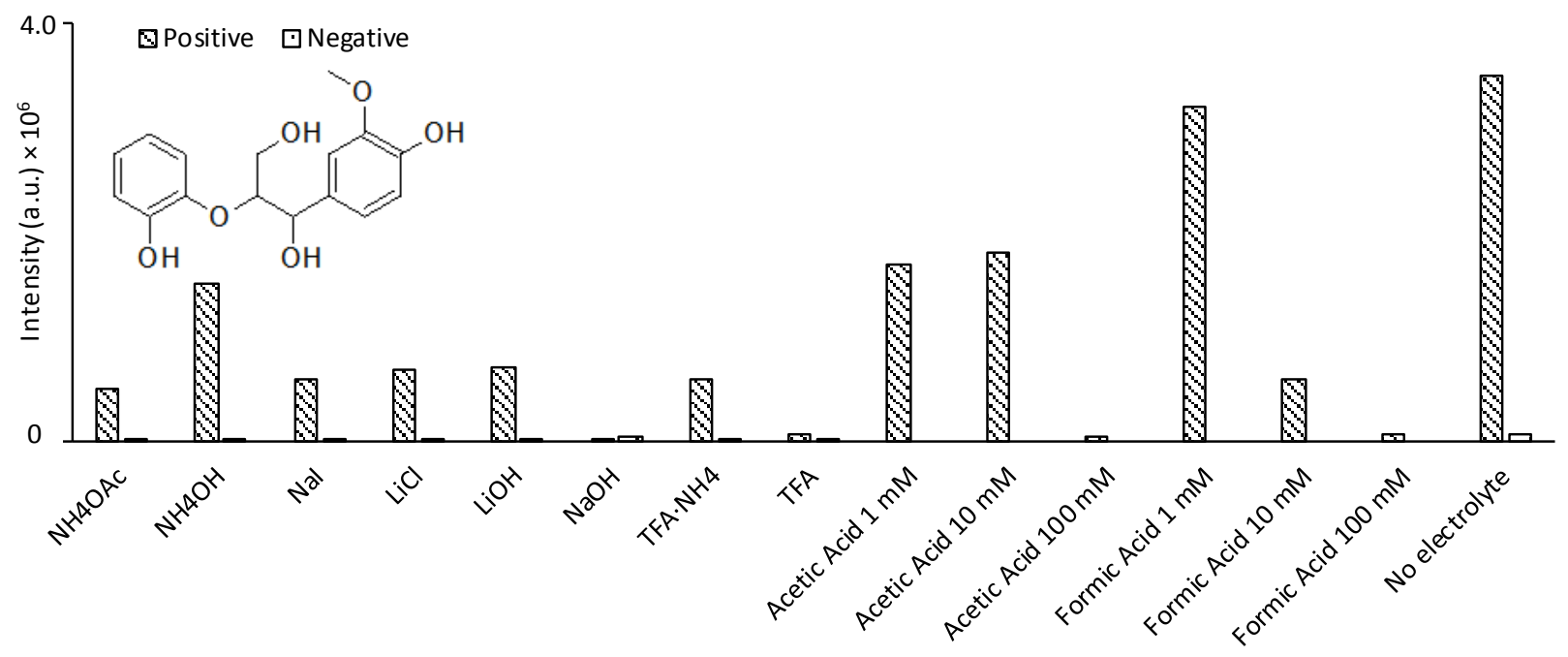

b)

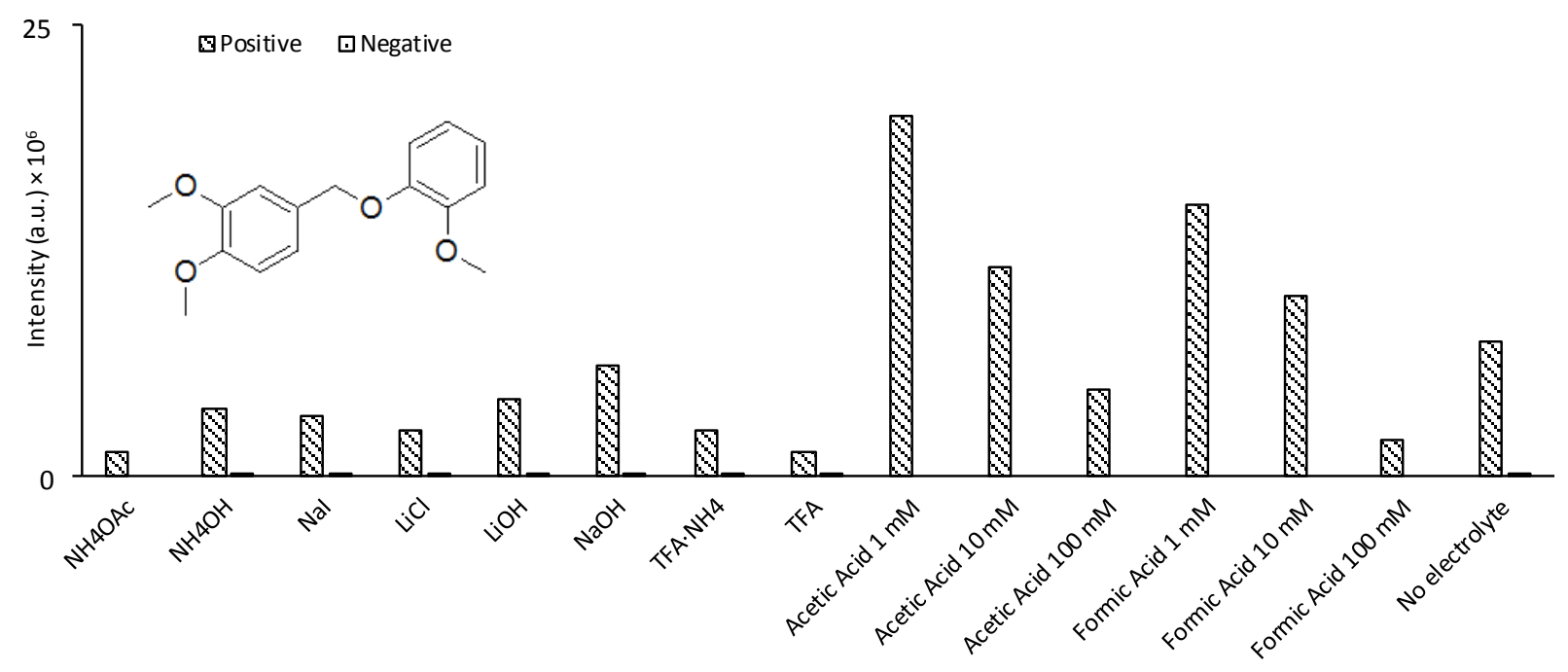

Figure 1. ESI TOF MS response obtained in the presence of different electrolytes via a direct infusion for two representative dimers (a) G-6-2; (b) ET2 in the positive and negative ionization modes. For most of the electrolytes used, the response for $[\mathrm{M}+\mathrm{Na}]^{+}$and deprotonated molecular ions is shown, except for $\mathrm{LiCl}$ and $\mathrm{LiOH}$ whose application resulted in the formation of $[\mathrm{M}+\mathrm{Li}]^{+}$. The electrolyte concentration was $1.0 \mathrm{mmol} \cdot \mathrm{L}^{-1}$ unless specified otherwise 
Figure 2. Positive ESI TOF mass spectra of 5 ppm G-6-2 $\left([\mathrm{M}+\mathrm{Na}]^{+} 343.1152 \mathrm{~m} / \mathrm{z}\right)$ in the presence of $1.0 \mathrm{mmol} \cdot \mathrm{L}^{-1}$ of a) ammonium acetate (mass accuracy error $5 \mathrm{ppm}$ ); b) acetic acid (mass accuracy error $7 \mathrm{ppm}$ ); and c) sodium hydroxide (mass accuracy error $6.7 \mathrm{ppm}$ ) 


\section{ESI: Impact of Oxygenated Functional Groups on Ionization}

Based on the screening experiments ( $c f$. Fig. 1), formic and acetic acids appeared to be the most efficient electrolytes. Thus, we compared these acids to frequently used ammonium acetate [73], to evaluate the impact of these electrolytes on the ionization effectiveness of a broader suite of mono-, di- and triarene lignin model compounds featuring different linkages and functional groups (Table 2), and investigated the contribution of various oxygenated functional groups: The results are shown in Table 3 . Contrary to the previously preferred negative ionization mode [45, 46], we showed ionization of all considered compounds (with hydroxyl, methoxy and carboxyl groups) in the positive ESI mode with both formic/acetic acids and ammonium acetate, although some selectivity toward specific oxygenated functional groups was observed.

The compounds without phenolic hydroxyl groups, with multiple methoxy groups, or with aliphatic hydroxyl groups, were preferentially ionized in the positive mode (the upper portion of Table 3) corroborating the results obtained earlier for non-acidic lignin model compounds [54, 55]. Thus the positive ESI mode is preferable as similar structural features, i.e., prevailing methoxy over phenolic hydroxyl functional groups, are also characteristic for alkali lignin (4.6 vs. 3.6 moles/1,000 $\mathrm{g}$ as claimed by the supplier).

While both electrolyte systems seemed to show satisfactory performance, acids were more effective for the majority of species with no hydroxyl groups and prevailing methoxy groups (Table 3). It is of note that some of the standards showed low response or could not be detected in the negative ESI mode at all, e.g., VER, EST2, ET2, ET3-1, SA, ET3-2, P2, G- $\beta-2$ ). This could perhaps be explained by the absence of hydroxyl groups or their steric hindrance (the structure motifs occurring in these molecules are shown in Table 2). For example, in case of syringaldehyde (SA) two $\mathrm{MeO}$ groups in the ortho-position to the hydroxyl moiety made the deprotonation of these compounds difficult. 
Table 3. ESI TOF MS Response with Acids (Either Formic or Acetic) and Ammonium Acetate as ESI Electrolytes for Representative Lignin Mono- to Trimeric Structure Model Compounds in both Positive and Negative Ionization Modes ${ }^{\mathrm{a}}$

\begin{tabular}{|c|c|c|c|c|c|c|c|c|}
\hline \multirow{3}{*}{ Model Compounds } & \multicolumn{4}{|c|}{ Numbers of Oxygenated Functional } & \multicolumn{4}{|c|}{ Intensity of the Target Ion Response } \\
\hline & \multicolumn{3}{|c|}{ Groups } & \multirow[t]{2}{*}{$\mathrm{p} K_{\mathrm{a}}$} & \multicolumn{2}{|c|}{ Acid (Formic/Acetic) } & \multicolumn{2}{|c|}{ Ammonium Acetate } \\
\hline & $-\mathrm{OH}$ & $-\mathrm{OCH}_{3}$ & $-\mathrm{COOH}$ & & Positive & Negative & Positive & Negative \\
\hline VER & $\mathbf{0}$ & 2 & 0 & - & $++++^{\mathrm{b}, \mathrm{c}}$ & $\mathrm{ND}^{\mathrm{d}}$ & +++ & ND \\
\hline EST2 & $\mathbf{0}$ & 1 & 0 & - & ++++ & ND & ++++ & ND \\
\hline ET2 & $\mathbf{0}$ & 3 & 0 & - & ++++ & ND & +++ & ND \\
\hline ET3-1 & $\mathbf{0}$ & 5 & 0 & - & ++++ & ND & +++ & ND \\
\hline ET3-2 & 1 & 5 & 0 & - & ++++ & + & +++ & + \\
\hline $\mathrm{P} 2$ & 2 & 2 & 0 & 9.76 & ++++ & + & +++ & + \\
\hline G- $\beta-2$ & $\begin{array}{c}1 \\
+\mathbf{2} \text { aliphatic }\end{array}$ & 2 & 0 & 9.88 & ++++ & + & +++ & + \\
\hline HA & $\begin{array}{c}1 \\
\mathbf{+ 1} \text { aliphatic }\end{array}$ & 1 & 0 & 10.19 & +++ & + & ++++ & ++ \\
\hline ALC2 & 1 aliphatic & 1 & 0 & & +++ & + & ++++ & ++ \\
\hline S & 1 & 2 & 0 & 9.98 & ++ & +++ & ++++ & + \\
\hline SA & 1 & 2 & 0 & 7.8 & +++ & + & ++++ & ++ \\
\hline
\end{tabular}




\footnotetext{
${ }^{a}$ For the majority of analytes, the response was monitored for $[\mathrm{M}+\mathrm{Na}]^{+}$and $[\mathrm{M}-\mathrm{H}]^{-}$ions in the positive and negative ionization modes, respectively. The electrolyte concentration upon direct infusion was $2.5 \mathrm{mmol} \cdot \mathrm{L}^{-1}$

b "++++" indicates the system resulting in the most efficient ionization; "+" indicates the system with the least efficient ionization

${ }^{c}$ The mass spectra recorded under the optimal conditions indicated as "++++" are shown in Supplementary Fig. 2 d "ND" denotes no molecular ions or adducts were detected
}

\section{Lignin ESI: Electrolyte Selection}

Similarly to lignin model compounds, electrolyte screening was performed for efficient ionization of lignin itself over a broad range of commonly used salts and acids in both the positive and negative modes. The urgent goal was to ensure an effective ionization of higher MW species forming high $\mathrm{m} / \mathrm{z}$ ions (Fig. 3). Formic acid at its highest concentrations of 100 and $200 \mathrm{mmol} \cdot \mathrm{L}^{-1}$ in the positive ESI mode enhanced the formation of multiply charged species. Following the deconvolution (as explained in the next section), this protocol allowed for detecting the masses of up to $9,000 \mathrm{Da}$ (Fig. 3b).

Under these conditions, the ionization of lower MW lignin model compounds was somewhat suppressed, yet sufficient for their effective detection ( $c f$. Fig. 1), thus providing more balanced mass spectra. 


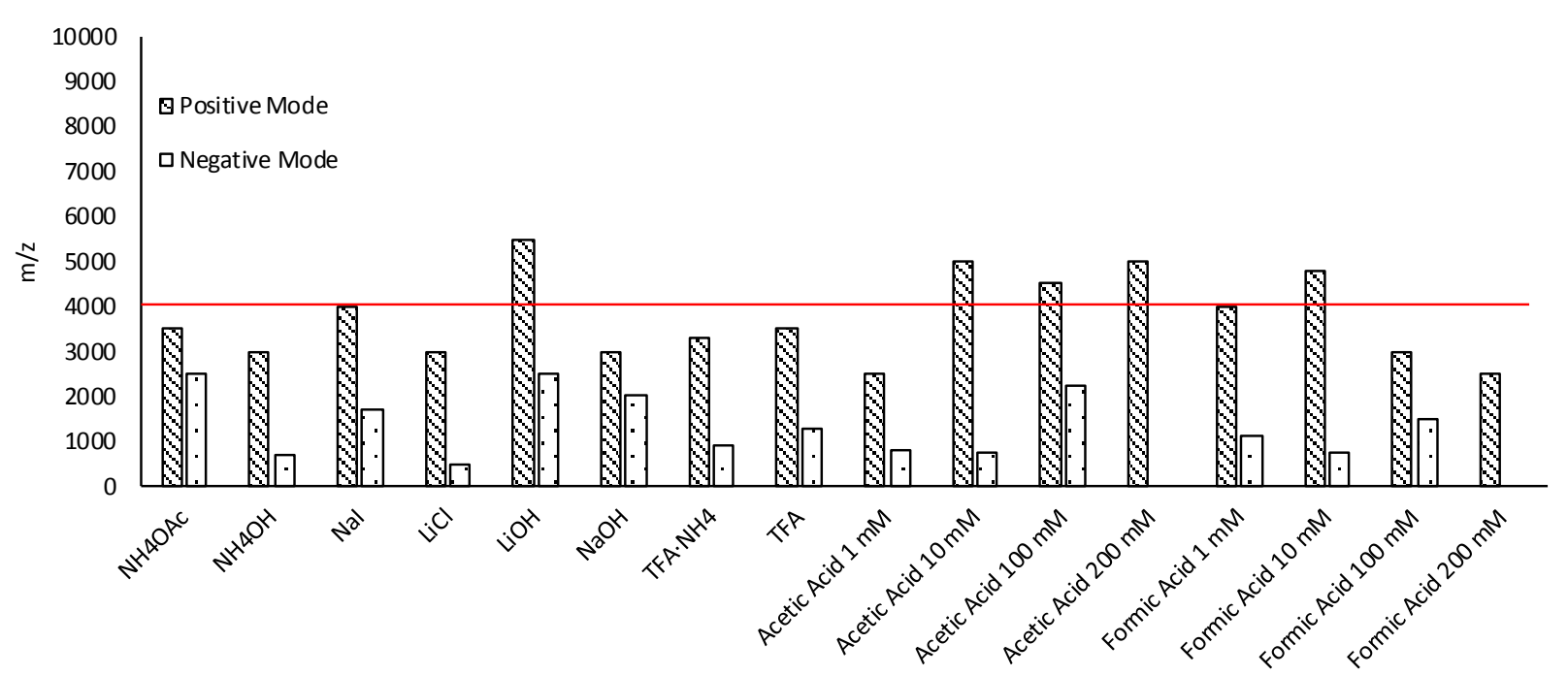


b) Intact alkali lignin. The highest MW (Da) after deconvolution of the mass spectra.

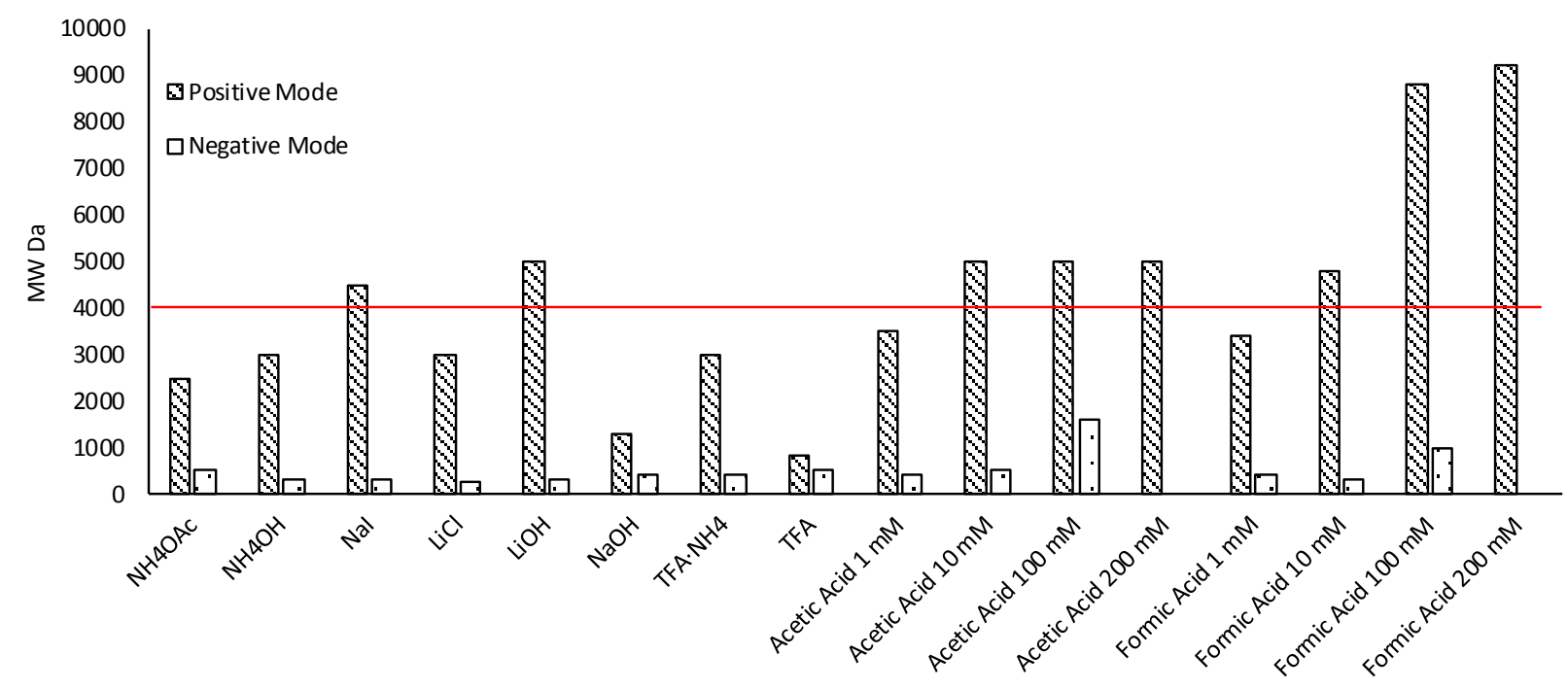

c) Acetylated alkali lignin. The highest $\mathrm{m} / \mathrm{z}$ prior to deconvolution.

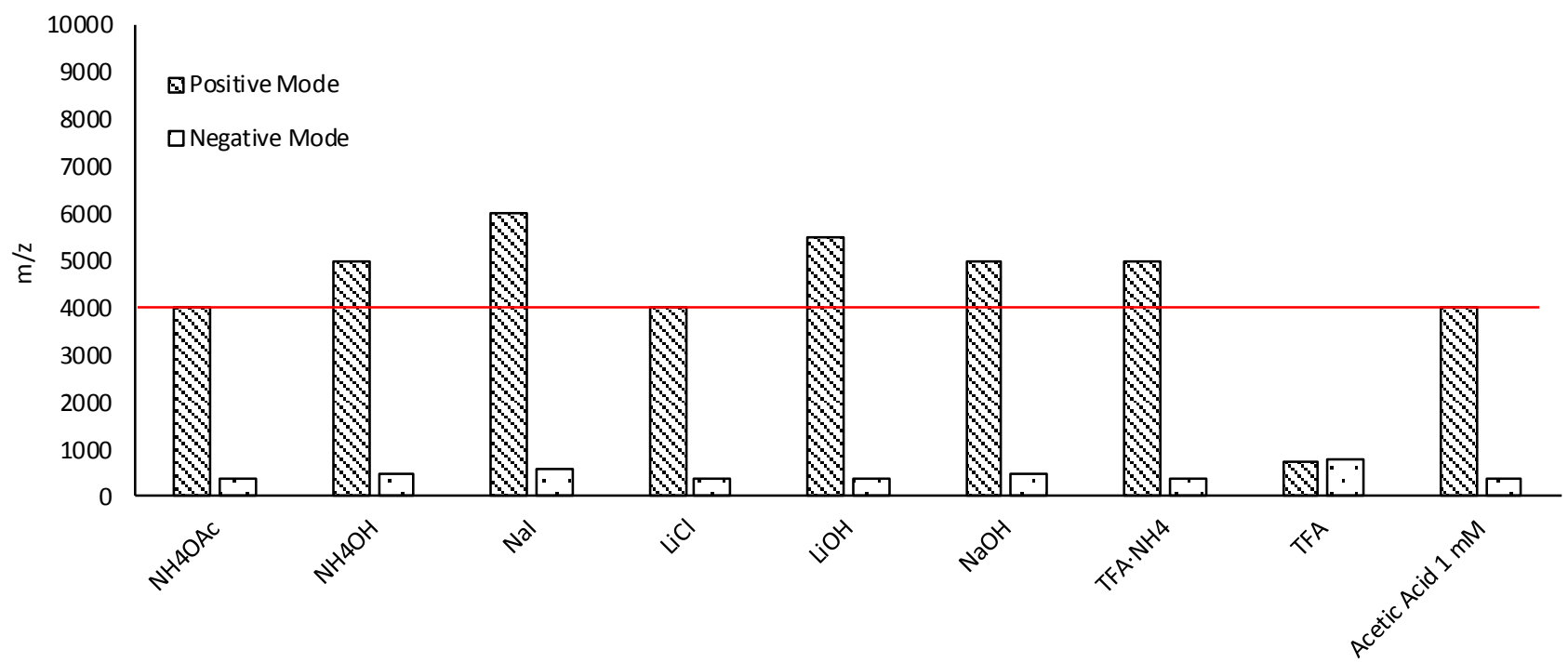




\section{Lignin ESI: Mass Spectrum Deconvolution}

ESI of lignin in the positive mode in the presence of $100 \mathrm{mmol} \cdot \mathrm{L}^{-1}$ formic acid allowed for minimizing the ionization discrimination. Thus, lower MW species were mainly observed as singly charged ions, whereas high MW lignin constituents carried multiple charges. For example, vanillin was detected as a singly charged ion of $153.0570 \mathrm{~m} / \mathrm{z}$ (protonated adduct $\left[\mathrm{C}_{8} \mathrm{H}_{8} \mathrm{O}_{3}+\mathrm{H}\right]^{+}, 16 \mathrm{ppm}$ mass accuracy error) (Fig. 4a). The corresponding deconvoluted species possessed a mass of 152.05 Da (Fig. 4b) calculated based on equations 1 and 5, which was equal to vanillin's MW.

$$
153.0570 \cdot 1-[(1.007825-0.000549) \cdot 1]=152.05 \mathrm{Da}
$$

High MW species were predominantly observed as multiply charged ions, for example the $597.2073 \mathrm{~m} / \mathrm{z}$ ion carried a charge of +7 (the spectrum is shown in Fig. $4 \mathrm{c}$ ). The mass spectrum 
deconvolution resulted in a calculated MW of 4173.40 for the corresponding species (equation 6), the spectrum is shown in Fig. 4d.

$$
597.2073 \cdot 7-[(1.007825-0.000549) \cdot 7]=4173.040 \mathrm{Da}
$$

a)

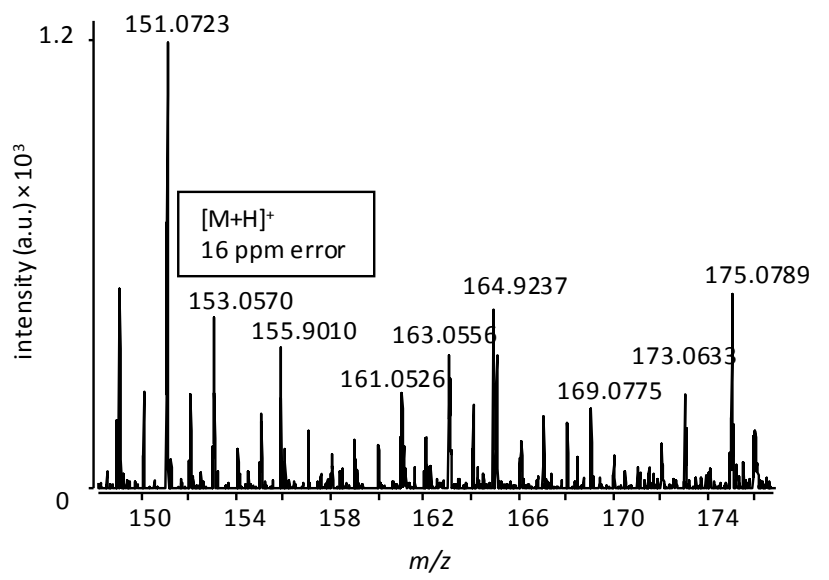

c)

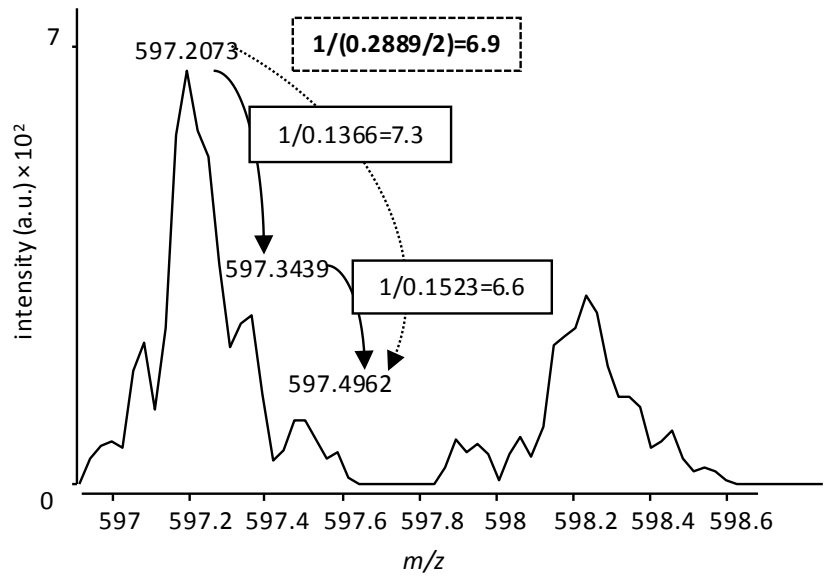

b)

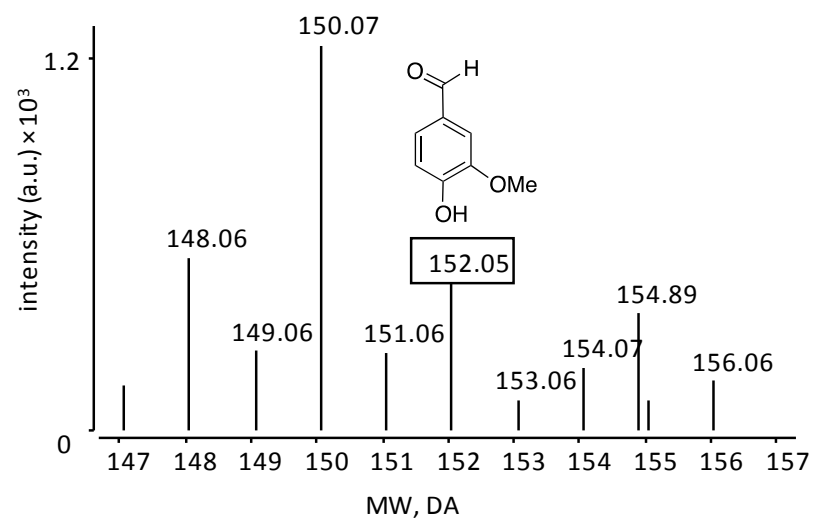

d)

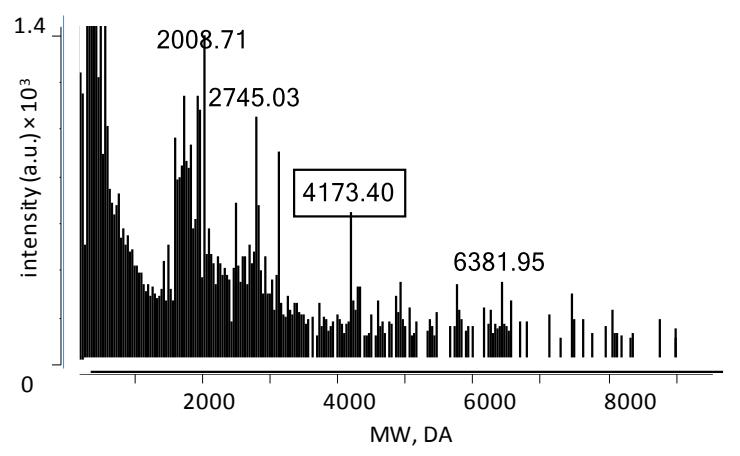


e)

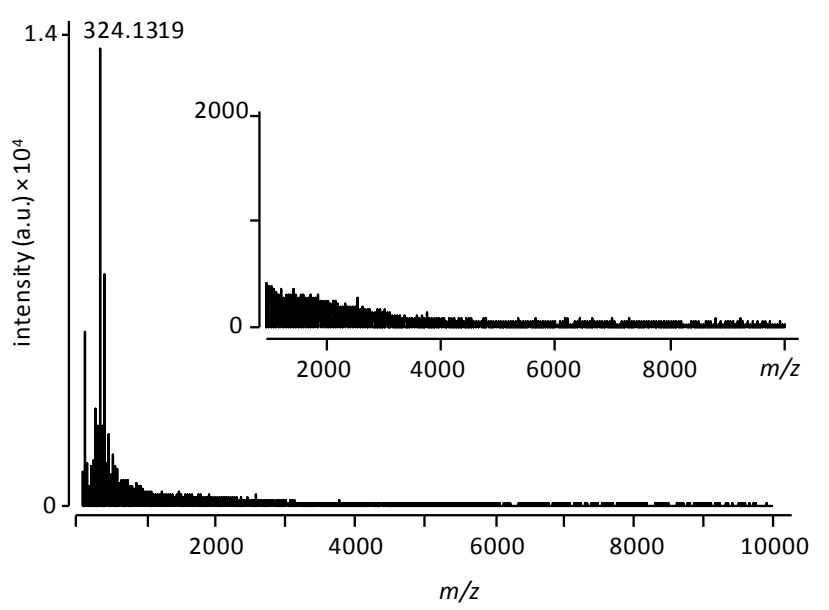

f)

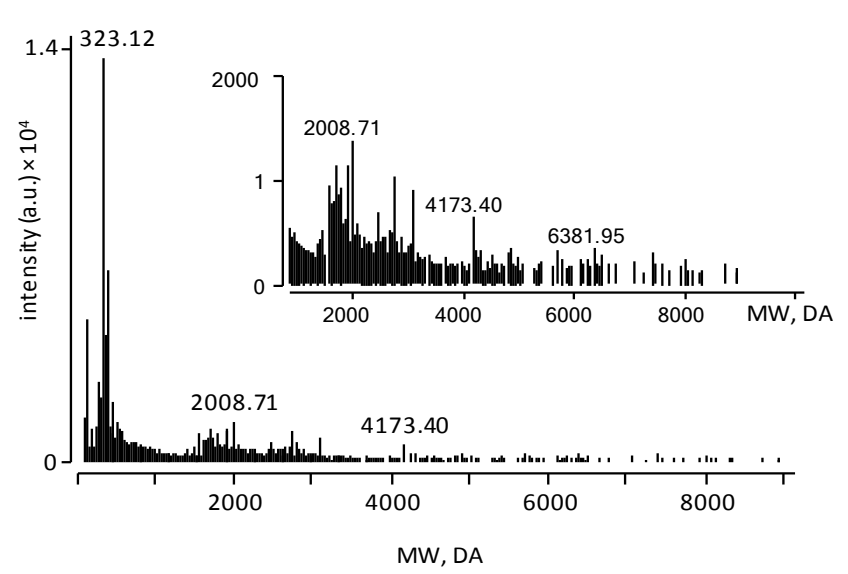

Figure 4. Positive ESI HR TOF mass spectra of an $80 \mathrm{ppm}$ solution of intact lignin in ACN-water (1:1) with $100 \mathrm{mmol} \cdot \mathrm{L}^{-1}$ formic acid: a), c) and e) zoomed and full original mass spectra; b), d) and f) zoomed and full mass spectra after deconvolution

Thus, analysis of lignin under the suggested ESI conditions allowed for a simultaneous determination of lignin constituents varying in size and structure via direct infusion analysis with minimal sample preparation. An introduced feature of the multiply charged ion formation allowed for an efficient ionization of high MW lignin species, which, to our knowledge, was not previously reported. This approach is an essential contribution to the lignomics toolkit allowing for analysis of higher MW species, as shown in the next section.

\section{Lignin MW Determination by ESI HR TOF MS}

To assess lignin MW, we previously adapted an approach from NIST [74] employing equations $2-4$ to the deconvoluted spectral data [11]. This calculation is typically used for evaluating GPC data rather than MS, yet, the obtained values, 1,480 Da, 2,520 Da and 3,790 Da 
for $\mathrm{M}_{\mathrm{n}}, \mathrm{M}_{\mathrm{w}}$ and $\mathrm{M}_{\mathrm{z}}$, respectively, were in good agreement with the MW values determined earlier by GPC (Table 4) [11]. Interestingly, similar MW values were determined for acetylated lignin, i.e., 1,570 Da, 2,440 Da and 3,530 Da for $\mathrm{M}_{\mathrm{n}}, \mathrm{M}_{\mathrm{w}}$ and $\mathrm{M}_{\mathrm{z}}$, respectively. This could be explained either by fragmentation with the loss leaving the most abundant molecular ions as ions

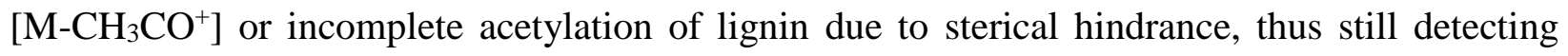
mostly intact lignin. In either case, it appears that the acetylated lignin MS data could also serve for the MW determination of the original, native lignin without a typical mass correction on acetylation.

Table 4. Number-Average, Weight-Average and z-Average Molecular Weight of Lignin Determined by ESI HR TOF MS, GPC and MALDI HR TOF MS

\begin{tabular}{cccc}
\hline & ESI HR TOF MS & GPC [11] & MALDI HR TOF MS \\
\hline $\mathrm{M}_{\mathrm{n}}$ & 1,480 & 1,630 & 830 \\
$\mathrm{M}_{\mathrm{w}}$ & 2,520 & 2,740 & 1,250 \\
$\mathrm{M}_{\mathrm{z}}$ & 3,790 & 3,720 & 2,230 \\
\hline
\end{tabular}

\section{Ionization: MALDI HR TOF MS vs. ESI HR TOF MS}

Similar mass spectra of intact lignin were recorded with MALDI and ESI as ionization sources (Fig. 5 compared to Fig. 4f). MALDI MS was selected as a reference technique frequently used for polymer MW determination [14, 34, 39, 40, 75-77]. To achieve the optimal lignin ESI, we evaluated the ionization efficiency with $\mathrm{CHCA}$ and $\mathrm{HABA}$ matrices and also without a matrix (Supplementary Fig. 3). The mass spectrum recorded with no matrix was of higher clarity, showing well resolved peaks of higher intensity above $2500 \mathrm{~m} / \mathrm{z}$. Apparently, the matrix structurally similar to lignin increased the background and complexity of spectra, perhaps, due to the undesirable association effects occurring during the sample co-crystallization with a matrix [38]. The recorded 
LDI mass spectrum (i.e., without a matrix) demonstrated several local maxima at 500, 1000, 2900, 4500 and $6200 \mathrm{~m} / \mathrm{z}$ (Fig. 5) with the decreasing signal at $\mathrm{m} / \mathrm{z}$ values of 7000 . The trends in the observed MALDI (LDI) and ESI HR TOF spectra were similar; however, ESI HR TOF MS allowed for obtaining a cleaner deconvoluted spectra for the high MW species.

We evaluated the LDI MS data using the calculations shown in equations $2-4$. The determined MW values agreed with the results obtained with GPC and ESI MS (Table 4). The MW elucidated while employing MALDI was shifted toward lower values, perhaps, due to the suppression of high MW species ionization because their detection was limited by the predominant formation of singly charged ions.

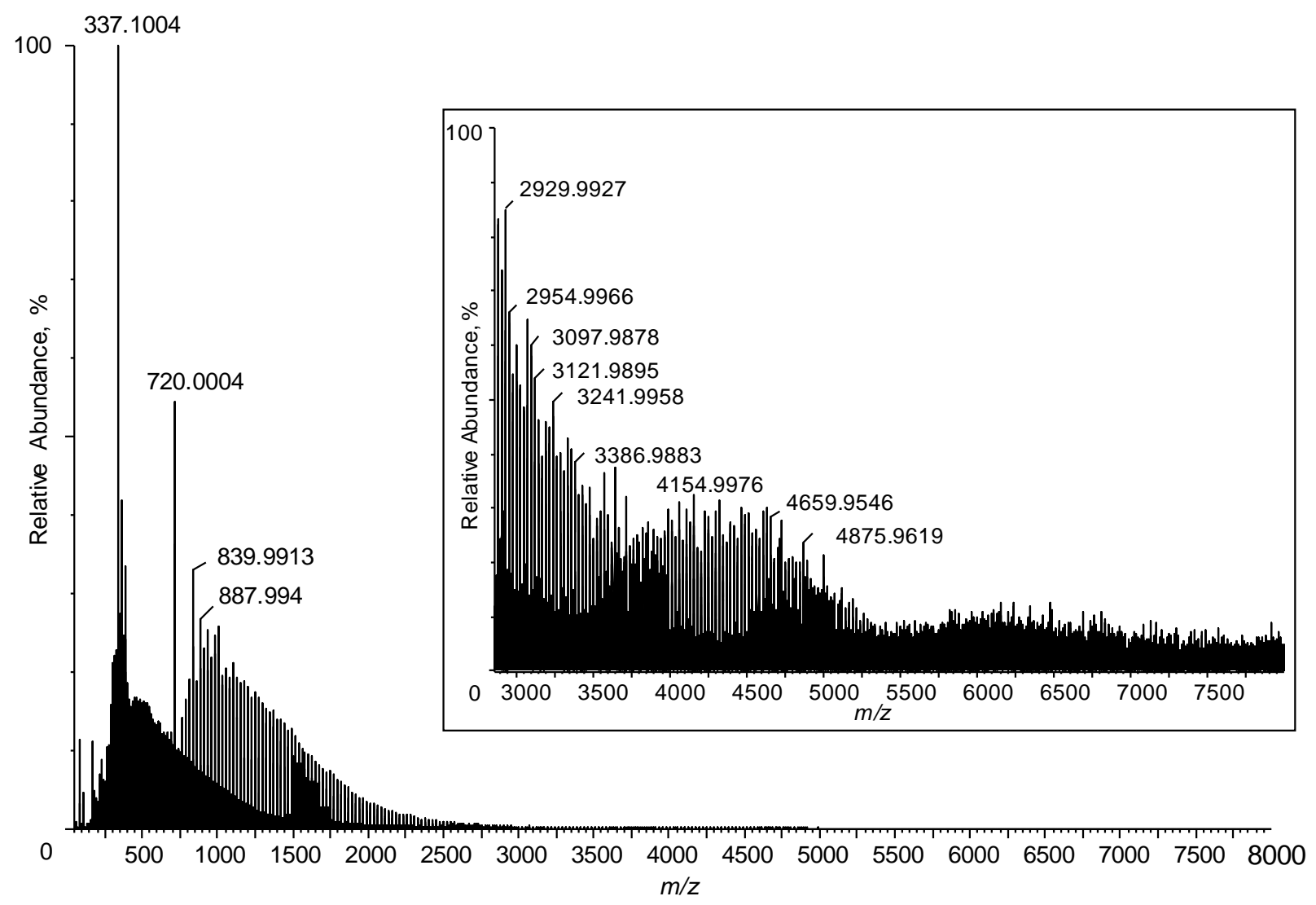

Figure 5. LDI (no matrix) HR TOF mass spectrum of alkali lignin. The insert shows a zoomed in part of the spectrum in the range $2800-8000 \mathrm{~m} / \mathrm{z}$ 


\section{Ion Mobility ESI MS: Confirmation of the Multiply Charged Species Formation}

To confirm the formation of multiply charged species, intact lignin was analyzed with IM ESI Q-TOF MS (Fig. 6a). Five distinguishable regions observed in the two-dimensional spectrum (drift time (ms) vs. $\mathrm{m} / \mathrm{z}$ ) suggest the occurrence of species carrying either varied charges or structural conformations (Fig. 6a). The deconvoluted positive IM ESI Q-TOF mass spectrum was similar to that recorded with the TOF MS (Fig. 6b compared to Fig. 4f). Species with a higher MW featured a higher abundance when analyzed by IM MS, as expected due to a better ion focusing typical for this technique. Notably, both deconvoluted spectra featured the same ion species observed after deconvolution. 
a)

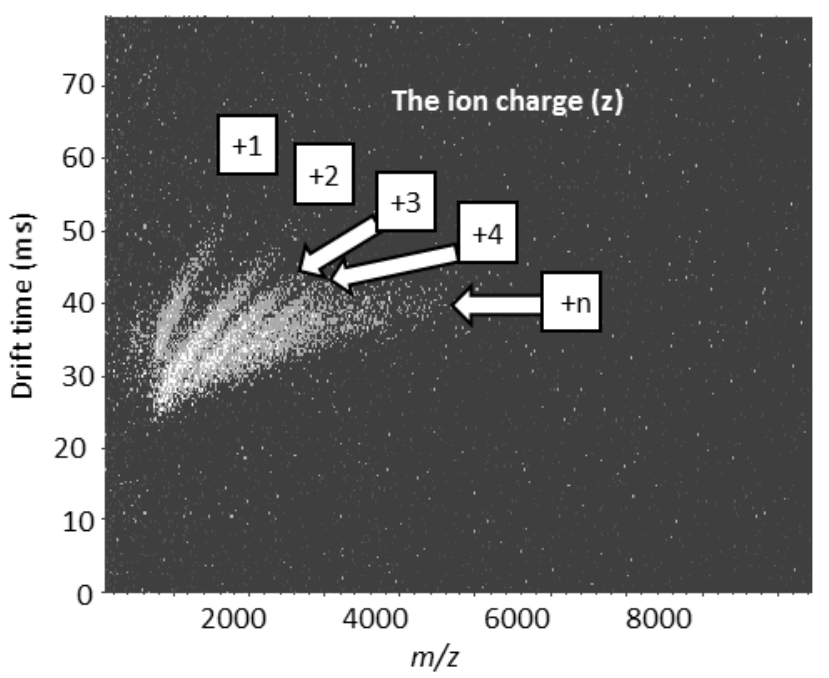

b)

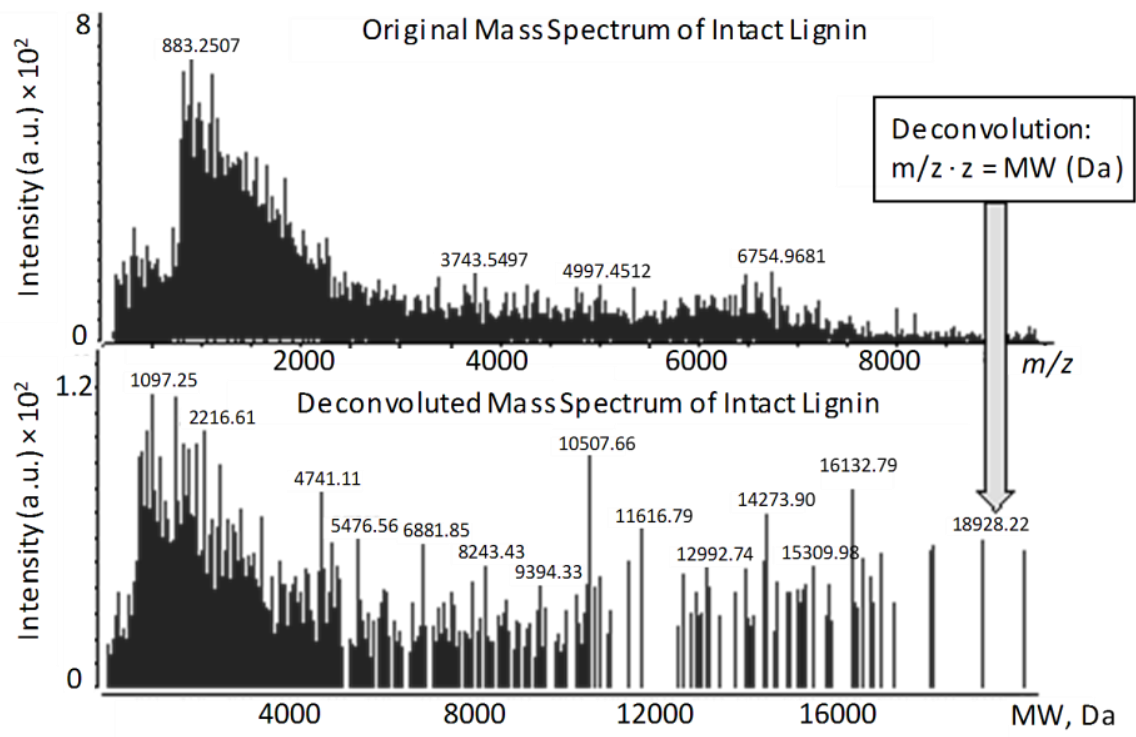

Fig. 6. a) Ion mobility image of a $100 \mathrm{ppm}$ solution of intact lignin in $A C N$-water (1:1) with $100 \mathrm{mmol} \cdot \mathrm{L}^{-1}$ formic acid, recorded in the positive ESI mode. b) Original and deconvoluted mass spectra of a $100 \mathrm{ppm}$ solution of intact lignin in ACN-water (1:1) with $100 \mathrm{mmol}^{-\mathrm{L}^{-1}}$ formic acid recorded in the positive ESI mode. The blank spectrum was subtracted before deconvolution. An accurate deconvolution algorithm is described in equation 1. 
With IM ESI HR Q-TOF MS, high MW species with masses up to 20,000 Da were observed, while ESI TOF MS allowed for the detection of species only up to 10,000 Da. This difference (compared to TOF MS) may be due to a higher sensitivity of the newer IM ESI Q-TOF instrument, possibly due to the IM feature allowing for a higher resolution and ion focusing.

\section{Conclusions}

An ESI TOF MS method for intact lignin analysis has been developed allowing for a simultaneous detection of both low and high MW species via direct infusion with minimal sample preparation. The most efficient ionization conditions were achieved in the positive ESI mode with $100 \mathrm{mmol} \cdot \mathrm{L}^{-1}$ formic acid as an electrolyte. For the first time, the formation of multiply charged ions promoting the ionization of high MW lignin species was shown. Determination of multiply charged ions was possible due to an inherently high resolving power of an applied HR TOF mass analyzer. To elucidate MW, the mass spectrum was deconvoluted. The obtained $M_{n}, M_{w}$, and $M_{z}$ values of 1,480 $\mathrm{Da}, 2,520 \mathrm{Da}$ and 3,790 $\mathrm{Da}$, respectively, were in good agreement with those determined previously for similar samples by gel permeation chromatography. The presence of multiply charged lignin ions was confirmed by IM MS using ESI IM HR Q-TOF MS. The developed method may extend the lignomics toolkit while targeting higher-MW species. 


\section{Acknowledgements}

We thank Dr. A. Ugrinov (NDSU) for his help with the MALDI TOF analysis and Dr. C. Zhang (SDSU) for synthesis of the lignin structure model compound G- $\beta-2$. We are grateful to J. Schumaker for his help with the detailed description of the syntheses of lignin model compounds and B. Nespor for his thorough review of the manuscript. The authors would like to acknowledge the funding by the National Science Foundation (NSF) ND EPSCoR DakotaBioCon IIA-1330840, CSMS and doctoral dissertation award IIA-1355466. Thomas DiProspero and Clayton Geib were supported through NSF Research Experience for Undergraduate students under Grants No. CHE 1460825 and CHE1156584. Any opinions, findings, and conclusions or recommendations expressed in this material are those of the author(s) and do not necessarily reflect the views of the NSF. 


\section{References}

1. Kang, S., Li, X., Fan, J., Chang, J.: Hydrothermal conversion of lignin: A review. Renew. Sust. Energ. Rev. 27, 546-558 (2013)

2. Reddy, S. N., Nanda, S., Dalai, A. K., Kozinski, J. A.: Supercritical water gasification of biomass for hydrogen production. Int. J. Hydrogen Energ. 39, 6912-6926 (2014)

3. Tian, C., Li, B., Liu, Z., Zhang, Y., Lu, H.: Hydrothermal liquefaction for algal biorefinery: A critical review. Renew. Sust. Energ. Rev. 38, 933-950 (2014)

4. Pu, Y., Hu, F., Huang, F., Davison, B. H., Ragauskas, A. J.: Assessing the molecular structure basis for biomass recalcitrance during dilute acid and hydrothermal pretreatments. Biotechnol. Biofuels 6, 1-13 (2013)

5. Ragauskas, A. J., Williams, C. K., Davison, B. H., Britovsek, G., Cairney, J., Eckert, C. A., Frederick, W. J., Jr., Hallett, J. P., Leak, D. J., Liotta, C. L., Mielenz, J. R., Murphy, R., Templer, R., Tschaplinski, T.: The path forward for biofuels and biomaterials. Science 311, 484489 (2006)

6. Lange, H., Decina, S., Crestini, C.: Oxidative upgrade of lignin - Recent routes reviewed. Eur. Polym. J. 49, 1151-1173 (2013)

7. Xu, C., Arancon, R. A., Labidi, J., Luque, R.: Lignin depolymerisation strategies: Towards valuable chemicals and fuels. Chem. Soc. Rev. 43, 7485-7500 (2014)

8. Upton, B. M., Kasko, A. M.: Strategies for the conversion of lignin to high-value polymeric materials: Review and perspective. Chem. Rev. 116, 2275-2306 (2016)

9. Kozliak, E. I., Kubátová, A., Artemyeva, A. A., Nagel, E., Zhang, C., Rajappagowda, R. B., Smirnova, A. L.: Thermal liquefaction of lignin to aromatics: Efficiency, selectivity and product analysis. ACS Sustain. Chem. Eng. 4, 5106-5122 (2016) 
10. Lange, H., Rulli, F., Crestini, C.: Gel permeation chromatography in determining molecular weights of lignins: Critical aspects revisited for improved utility in the development of novel materials. ACS Sustain. Chem. Eng. 4, 5167-5180 (2016)

11. Andrianova, A. A., Yeudakimenka, N. A., Lilak, S. L., Kozliak, E. I., Ugrinov, A., Sibi, M. P., Kubátová, A.: Size exclusion chromatography of lignin: The mechanistic aspects and elimination of undesired secondary interactions. J. Chromatogr., A submitted, (2017)

12. Hortling, B., Turunen, E., Kokkonen, P.: Molar mass and size distribution of lignins. In: Wu, C. S. (ed.). Marcel Dekker, New York, (2004)

13. Faix, O., Beinhoff, O.: Improved calibration of highperformance size-exclusion chromatography of lignins using lignin-like model compounds. Holzforschung 46, 355-356 (1992)

14. Banoub, J., Delmas, G. H., Jr., Joly, N., Mackenzie, G., Cachet, N., Benjelloun-Mlayah, B., Delmas, M.: A critique on the structural analysis of lignins and application of novel tandem mass spectrometric strategies to determine lignin sequencing. J. Mass Spectrom. 50, 5-48 (2015) 15. Uliyanchenko, E., van der Wal, S., Schoenmakers, P. J.: Challenges in polymer analysis by liquid chromatography. Polym. Chem. 3, 2313-2335 (2012)

16. Gidh, A. V., Decker, S. R., Vinzant, T. B., Himmel, M. E., Williford, C.: Determination of lignin by size exclusion chromatography using multi angle laser light scattering. J. Chromatogr., A 1114, 102-110 (2006)

17. Gidh, A. V., Decker, S. R., Vinzant, T. B., Himmel, M. E., Williford, C. W.: Fungalinduced redistribution of kraft lignin molecular weight by multi-angle laser light scattering. Chem. Eng. Commun. 193, 1546-1561 (2006) 
18. Cathala, B., Saake, B., Faix, O., Monties, B.: Association behaviour of lignins and lignin model compounds studied by multidetector size-exclusion chromatography. J. Chromatogr., A 1020, 229-239 (2003)

19. Fredheima, G. E., Braatenb, S. M., Christensen, B. E.: Molecular weight determination of lignosulfonates by size-exclusion chromatography and multi-angle laser light scattering. J. Chromatogr., A 942, 191-199 (2002)

20. Braaten, S. M., Christensen, B. E., Fredheim, G. E.: Comparison of molecular weight and molecular weight distributions of softwood and hardwood lignosulfonates. J. Wood Chem. Technol. 23, 197-215 (2003)

21. Ringena, O., Lebioda, S., Lehnen, R., Saake, B.: Size-exclusion chromatography of technical lignins in dimethyl sulfoxide/water and dimethylacetamide. J. Chromatogr., A 1102, $154-163(2006)$

22. Reale, S., Di Tullio, A., Spreti, N., De Angelis, F.: Mass spectrometry in the biosynthetic and structural investigation of lignins. Mass Spectrom. Rev. 23, 87-126 (2004)

23. Kleen, M., Ohra-aho, T., Tamminen, T.: On the interaction of HBT with pulp lignin during mediated laccase delignification - a study using fractionated pyrolysis-GC/MS. J. Anal. Appl. Pyr. 70, 589-600 (2003)

24. Del Río, J. C., Gutiérrez, A., Martínez, Á. T.: Identifying acetylated lignin units in nonwood fibers using pyrolysis-gas chromatography/mass spectrometry. Rapid Commun. Mass Spectrom. 18, 1181-1185 (2004)

25. Ke, J., Laskar, D. D., Chen, S.: Varied lignin disruption mechanisms for different biomass substrates in lower termite. Renewable Energy 50, 1060-1064 (2013) 
26. Mullen, C. A., Boateng, A. A.: Catalytic pyrolysis-GC/MS of lignin from several sources. Fuel Proc. Technol. 91, 1446-1458 (2010)

27. Klingberg, A., Odermatt, J., Meier, D.: Influence of parameters on pyrolysis-GC/MS of lignin in the presence of tetramethylammonium hydroxide. J. Anal. Appl. Pyr. 74, 104-109 (2005)

28. Kuroda, K.-i., Izumi, A., Mazumder, B. B., Ohtani, Y., Sameshima, K.: Characterization of kenaf (Hibiscus cannabinus) lignin by pyrolysis-gas chromatography-mass spectrometry in the presence of tetramethylammonium hydroxide. J. Anal. Appl. Pyr. 64, 453-463 (2002)

29. Greenwood, P. F., van Heemst, J. D. H., Guthrie, E. A., Hatcher, P. G.: Laser micropyrolysis GC-MS of lignin. J. Anal. Appl. Pyr. 62, 365-373 (2002)

30. Britt, P. F., Buchanan, A. C., Evans, R. J., Looker, M., Nimlos, M. R.: Investigation of the gas-phase pyrolysis of lignin model compounds by molecular beam mass spectrometry. Conference Proceedings, Fuel Chemistry Division Preprints, (2002)

31. Del Río, J. C., Gutiérrez, A., Romero, J., Martínez, M. J., Martínez, A. T.: Identification of residual lignin markers in eucalypt kraft pulps by Py-GC/MS. J. Anal. Appl. Pyr. 58-59, 425$439(2001)$

32. Hansen, B., Kusch, P., Schulze, M., Kamm, B.: Qualitative and quantitative analysis of lignin produced from beech wood by different conditions of the organosolv process. J. Polym. Environ., 1-13 (2016)

33. Hu, J., Shen, D., Wu, S., Zhang, H., Xiao, R.: Composition analysis of organosolv lignin and its catalytic solvolysis in supercritical alcohol. Energy Fuels 28, 4260-4266 (2014) 
34. Kosyakov, D. S., Ul'yanovskii, N. V., Sorokina, E. A., Gorbova, N. S.: Optimization of sample preparation conditions in the study of lignin by MALDI mass spectrometry. J. Anal. Chem. 69, 1344-1350 (2014)

35. Richel, A., Vanderghem, C., Simon, M., Wathelet, B., Paquot, M.: Evaluation of matrixassisted laser desorption/ionization mass spectrometry for second-generation lignin analysis. Anal. Chem. Insights 7, 79-89 (2012)

36. Yoshioka, K., Ando, D., Watanabe, T.: A comparative study of matrix- and nano-assisted laser desorption/ionisation time-of-flight mass spectrometry of isolated and synthetic lignin. Phytochem. Anal. 23, 248-253 (2012)

37. Song, Q., Wang, F., Cai, J., Wang, Y., Zhang, J., Yu, W., Xu, J.: Lignin depolymerization (LDP) in alcohol over nickel-based catalysts via a fragmentation-hydrogenolysis process. Energ. Environ. Sci. 6, 994-1007 (2013)

38. Evtuguin, D. V., Domingues, P., Amado, F. L., Pascoal Neto, C., Ferrer Correia, A. J.: Electrospray ionization mass spectrometry as a tool for lignins molecular weight and structural characterisation. Holzforschung 53, 525-528 (1999)

39. Jacobs, A., Dahlman, O.: Absolute molar mass of lignins by size exclusion chromatography and MALDI-TOF mass spectroscopy. Nord. Pulp Pap. Res. J. 15, 120-127 (2000)

40. Bayerbach, R., Nguyen, V. D., Schurr, U., Meier, D.: Characterization of the waterinsoluble fraction from fast pyrolysis liquids (pyrolytic lignin). J. Anal. Appl. Pyr. 77, 95-101 (2006)

41. Banoub, J. H., Benjelloun-Mlayah, B., Ziarelli, F., Joly, N., Delmas, M.: Elucidation of the complex molecular structure of wheat straw lignin polymer by atmospheric pressure 
photoionization quadrupole time-of-flight tandem mass spectrometry. Rapid Commun. Mass Spectrom. 21, 2867-2888 (2007)

42. Morreel, K., Dima, O., Kim, H., Lu, F., Niculaes, C., Vanholme, R., Dauwe, R., Goeminne, G., Inze, D., Messens, E., Ralph, J., Boerjan, W.: Mass spectrometry-based sequencing of lignin oligomers. Plant Physiol. 153, 1464-1478 (2010)

43. Raghuraman, A., Tiwari, V., Thakkar, J. N., Gunnarsson, G. T., Shukla, D., Hindle, M., Desai, U. R.: Structural characterization of a serendipitously discovered bioactive macromolecule, lignin sulfate. Biomacromolecules 6, 2822-2832 (2005)

44. Banoub, J. H., Delmas, M.: Structural elucidation of the wheat straw lignin polymer by atmospheric pressure chemical ionization tandem mass spectrometry and matrix-assisted laser desorption/ionization time-of-flight mass spectrometry. J. Mass Spectrom. 38, 900-903 (2003) 45. Kiyota, E., Mazzafera, P., Sawaya, A. C.: Analysis of soluble lignin in sugarcane by ultrahigh performance liquid chromatography-tandem mass spectrometry with a do-it-yourself oligomer database. Anal. Chem. 84, 7015-7020 (2012)

46. Morreel, K., Kim, H., Lu, F., Dima, O., Akiyama, T., Vanholme, R., Niculaes, C., Goeminne, G., Inzé, D., Messens, E., Ralph, J., Boerjan, W.: Mass spectrometry-based fragmentation as an identification tool in lignomics. Anal. Chem. 82, 8095-8105 (2010)

47. Kosyakov, D. S., Ul'yanovskii, N. V., Anikeenko, E. A., Gorbova, N. S.: Negative ion mode atmospheric pressure ionization methods in lignin mass spectrometry: A comparative study. Rapid Commun. Mass Spectrom. 30, 2099-2108 (2016)

48. D'Auria, M., Emanuele, L., Racioppi, R.: FT-ICR-MS analysis of lignin. Nat. Prod. Res. 26, 1368-1374 (2012) 
49. Evtuguin, D. V., Amado, F. M. L.: Application of electrospray ionization mass spectrometry to the elucidation of the primary structure of lignin. Macromolecular Bioscience $\mathbf{3}$, $339-343(2003)$

50. De Angelis, F. N., Rosario; Spreti, Nicoletta; Verì, Franca A new in vitro model of lignin biosynthesis. Angew. Chem. Int. Ed. 38, 1283-1285 (1999)

51. Munisamy, S. M., Chambliss, C. K., Becker, C.: Direct infusion electrospray ionizationion mobility high resolution mass spectrometry (DIESI-IM-HRMS) for rapid characterization of potential bioprocess streams. J. Am. Soc. Mass Spectrom. 23, 1250-1259 (2012)

52. Parker, C. E., Warren, M. R., Mocanu, V.: Mass Spectrometry for Proteomics. In: Alzate O (ed.). CRC Press/Taylor \& Francis, Boca Raton (FL), (2010)

53. Pinto, P. C., Evtuguin, D. V., Neto, C. P., Silvestre, A. J. D., Amado, F. M. L.: Behavior Ofeucalyptus Globuluslignin during kraft pulping. II. Analysis by NMR, ESI/MS, and GPC. J. Wood Chem. Technol. 22, 109-125 (2002)

54. Haupert, L. J., Owen, B. C., Marcum, C. L., Jarrell, T. M., Pulliam, C. J., Amundson, L. M., Narra, P., Aqueel, M. S., Parsell, T. H., Abu-Omar, M. M., Kenttämaa, H. I.: Characterization of model compounds of processed lignin and the lignome by using atmospheric pressure ionization tandem mass spectrometry. Fuel 95, 634-641 (2012)

55. Owen, B. C., Haupert, L. J., Jarrell, T. M., Marcum, C. L., Parsell, T. H., Abu-Omar, M. M., Bozell, J. J., Black, S. K., Kenttamaa, H. I.: High-performance liquid chromatography/highresolution multiple stage tandem mass spectrometry using negative-ion-mode hydroxide-doped electrospray ionization for the characterization of lignin degradation products. Anal. Chem. 84, 6000-6007 (2012) 
56. Araujo, P., Ferreira, M. S., de Oliveira, D. N., Pereira, L., Sawaya, A. C., Catharino, R. R., Mazzafera, P.: Mass spectrometry imaging: An expeditious and powerful technique for fast in situ lignin assessment in Eucalyptus. Anal. Chem. 86, 3415-3419 (2014)

57. Navarrete, P. P., A.; Pasch, H.; Delmotte, L.: Study on lignin-glyoxal reaction by MALDITOF and CP-MAS ${ }^{13}$ C-NMR. J. Adhes. Sci. Technol. 26, 1069-1082 (2012)

58. Bocchini, P., Galletti, G. C., Seraglia, R., Traldi, P., Camarero, S., Martinezd, A. T.: Matrix-assisted laser desorption/ionization mass spectrometry of natural and synthetic lignin. Rapid Commun. Mass Spectrom. 10, 1144-1147 (1996)

59. Awal, A., Sain, M.: Spectroscopic studies and evaluation of thermorheological properties of softwood and hardwood lignin. J. Appl. Polym. Sci. 122, 956-963 (2011)

60. Kleen, M.: Surface lignin and extractives on hardwood RDH kraft pulp chemically characterized by ToF-SIMS. Holzforschung 59, (2005)

61. Kawai, S., Okita, K., Sugishita, K., Tanaka, A., Ohash, H.: Simple method for synthesizing phenolic $\beta$-O-4 dilignols. J. Wood Sci. 45, 440-443 (1999)

62. Zakis, G. F.: Synthesis of Lignin Model Compounds. Zinatne, Riga (1980)

63. Elbs, K. J.: Uber dehydrodivanillin. J. Prakt. Chem. 93, 1-8 (1916)

64. Gaur, M., Lohani, J., Balakrishnan, V. R., Raghunathan, P., Eswaran, S. V.: Dehydrodivanillin: Multi-dimensional NMR Spectral Studies, Surface Morphology and Electrical Characteristics of Thin Films. Bulletin of the Korean Chemical Society 30, 2895-2898 (2009)

65. Gaur, M., Lohani, J., Balakrishnan, V. R., Raghunathan, P., Eswaran, S. V.: Dehydrodivanillin: Multi-dimensional NMR spectral studies, surface morphology and electrical characteristics of thin films. Bull. Korean Chem. Soc. 30, 2895-2898 (2009) 
66. Gosselink, R. J. A., Abächerli, A., Semke, H., Malherbe, R., Käuper, P., Nadif, A., van Dam, J. E. G.: Analytical protocols for characterisation of sulphur-free lignin. Ind. Crops Prod. 19, 271-281 (2004)

67. Glasser, W. G., Jain, R. K.: Lignin derivatives. I. Alkanoates. Holzforschung 47, 225-233 (1993)

68. Popova, I. E., Hall, C., Kubátová, A.: Determination of lignans in flaxseed using liquid chromatography with time-of-flight mass spectrometry. J. Chromatogr., A 1216, 217-229 (2009) 69. Strohalm, M., Hassman, M., Košata, B., Kodíček, M.: mMass data miner: an open source alternative for mass spectrometric data analysis. Rapid Commun. Mass Spectrom. 22, 905-908 (2008)

70. Young, R. J., Lovell, P. A.: Introduction to Polymers. Nelson Thornes, Cheltenham, UK (2002)

71. Sforza, S., Galaverna, G., Corradini, R., Dossena, A., Marchelli, R.: ESI-mass spectrometry analysis of unsubstituted and disubstituted $\beta$-cyclodextrins: fragmentation mode and identification of the AB, AC, AD regioisomers. J. Am. Soc. Mass Spectrom. 14, 124-135 (2003)

72. Dongari, N., Sauter, E. R., Tande, B. M., Kubátová, A.: Determination of Celecoxib in human plasma using liquid chromatography with high resolution time of flight-mass spectrometry. J. Chromatogr. B Analyt. Technol. Biomed. Life Sci. 955-956, 86-92 (2014)

73. Hernandez, H., Robinson, C. V.: Determining the stoichiometry and interactions of macromolecular assemblies from mass spectrometry. Nat Protoc 2, 715-726 (2007) 
74. Wallace, W. E., Guttman, C. M.: NIST Recommended Practice Guide. Molecular Mass Distribution Measurement by Mass Spectrometry. National Institute of Standards and Technology U.S. Department of Commerce (2010)

75. Gosselink, R. J. A.: Lignin as a renewable aromatic resource for the chemical industry. Ph.D. Dissertation, Wageningen University, Wageningen, NL (2011)

76. Mattinen, M.-L., Suortti, T., Gosselink, R., Argyropoulos, D. S., Evtuguin, D., Suurnakki, A., Jong, E., Tamminen, T.: Polymerization of different lignins by laccase. Bioresources 3, 549$565(2008)$

77. Mattinen, M. L., Maijala, P., Nousiainen, P., Smeds, A., Kontro, J., Sipilä, J., Tamminen, T., Willför, S., Viikari, L.: Oxidation of lignans and lignin model compounds by laccase in aqueous solvent systems. J. Mol. Catal. B: Enzym. 72, 122-129 (2011) 


\begin{tabular}{|c|c|c|c|c|c|}
\hline Ionization & Mass Analyzer & Analyte & Solvent & Electrolyte/ & MW or $m / z$ \\
\hline Mode & & & & MALDI Matrix & Range Detected \\
\hline
\end{tabular}

ESI

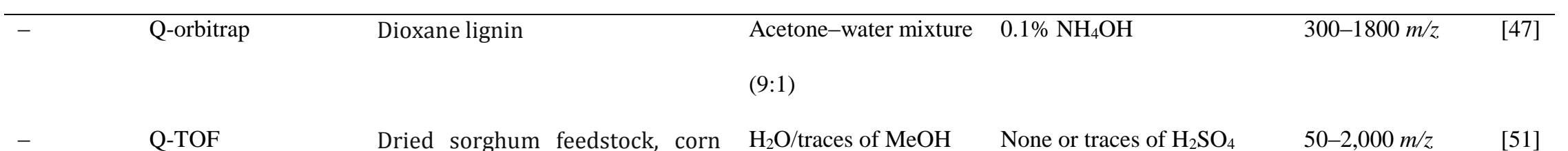

Q-TOF

stover hydrolysate, xylobiose and

xylotetraose

${ }^{1}$ with a maximum at $2 \cdot 10^{3} \mathrm{~g} \cdot \mathrm{mol}^{-1}$

Fourier transform

according to GPC);

hybrid linear trap/7- steam explosion lignin

T Fourier transform

- ion cyclotron

resonance MS

Magnetic sector Spruce and eucalyptus dioxane

Q-TOF

Low-molecular-weight fraction of $\mathrm{MeOH} / \mathrm{H}_{2} \mathrm{O}$

$(1: 1) / 0.25 \% \mathrm{NH}_{3}$ 


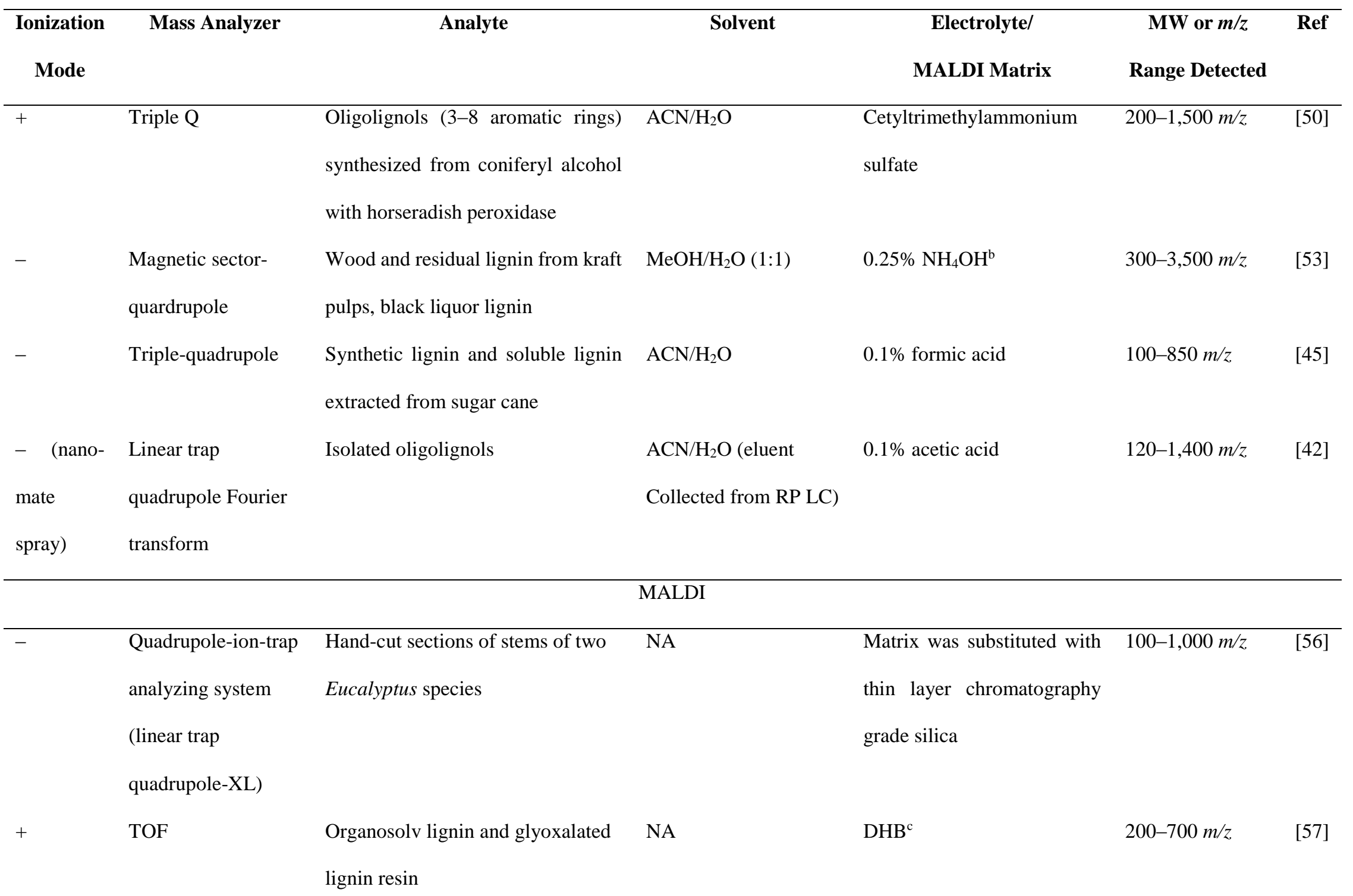




\begin{tabular}{|c|c|c|c|c|c|c|}
\hline $\begin{array}{c}\text { Ionization } \\
\text { Mode }\end{array}$ & Mass Analyzer & Analyte & Solvent & $\begin{array}{c}\text { Electrolyte/ } \\
\text { MALDI Matrix }\end{array}$ & $\begin{array}{c}\text { MW or } m / z \\
\text { Range Detected }\end{array}$ & Ref \\
\hline+ & TOF & $\begin{array}{l}\text { Bagasse lignin }\left(100-100,000 \mathrm{~g} \cdot \mathrm{mol}^{-}\right. \\
{ }^{1} \text { with a maximum at } 2 \cdot 10^{3} \mathrm{~g} \cdot \mathrm{mol}^{-1} \\
\text { according to GPC); } \\
\text { steam explosion lignin }\end{array}$ & NA & DHB & $\begin{array}{l}\text { Mass distribution } \\
\text { with a maximum } \\
\text { around } m / z 360 \text {; } \\
\text { no signal above } \\
2000 \mathrm{~m} / \mathrm{z}\end{array}$ & {$[48]$} \\
\hline$+1-$ & TOF & $\begin{array}{l}\text { Lignin fractions extracted from } \\
\text { Miscanthus } x \text { giganteus under } \\
\text { alkali or acid conditions }\end{array}$ & NA & $\mathrm{CHCA}^{\mathrm{d} / \alpha \text {-cyclodextrin }}$ & $100-800 \mathrm{Da}$ & [35] \\
\hline$+/-$ & TOF & $\begin{array}{l}\text { Ssoftwood kraft lignin, mixed } \\
\text { hardwood organosolv lignin, acid } \\
\text { hydrolysis lignin from bagasse, and } \\
\text { steam explosion lignin from aspen } \\
\text { (acetylated sample) }\end{array}$ & NA & $\begin{array}{l}\text { DHB or all-trans-retinoic } \\
\text { acid }\end{array}$ & $\begin{array}{l}50-14,000 \mathrm{~m} / \mathrm{z} \\
\text { (unresolved at } \\
\text { higher } \mathrm{m} / \mathrm{z} \text { ); } 50- \\
14,000 \mathrm{Da} \\
\text { (singly charged } \\
\text { ions are almost } \\
\text { exclusively } \\
\text { generated) }\end{array}$ & [39] \\
\hline
\end{tabular}




\begin{tabular}{|c|c|c|c|c|c|c|}
\hline $\begin{array}{c}\text { Ionization } \\
\text { Mode }\end{array}$ & Mass Analyzer & Analyte & Solvent & $\begin{array}{c}\text { Electrolyte/ } \\
\text { MALDI Matrix }\end{array}$ & $\begin{array}{c}\text { MW or } m / z \\
\text { Range Detected }\end{array}$ & Ref \\
\hline & & $\begin{array}{l}\text { obtained by enzymic } \\
\text { polymerization of coniferyl alcohol }\end{array}$ & & $\begin{array}{lll}\text { Sinapinic acid } & \text { was } \\
\text { preferred.) } & & \end{array}$ & 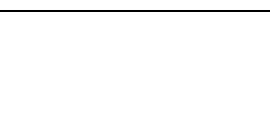 & \\
\hline$+/-$ & $\begin{array}{l}\text { Quadrupole ion trap } \\
\text { TOF (QIT-TOF) }\end{array}$ & Dioxane lignin & NA & $\begin{array}{l}N \text {-tert-butyl- } N \text {-isopropyl- } N \text { - } \\
\text { methylammonium } \alpha \text {-cyano- } \\
\text { 4-hydroxycinnamate ionic } \\
\text { liquid or no matrix. The } \\
\text { latter provided poor spectral } \\
\text { data. }\end{array}$ & $\begin{array}{l}50-2,000 \mathrm{Da} \\
\text { (unresolved) and } \\
2000-6000 \mathrm{Da} \\
\text { (unresolved) }\end{array}$ & [34] \\
\hline+ & TOF & $\begin{array}{l}\text { Milled wood lignin and synthetic } \\
\text { lignin (polymerisation of coniferyl } \\
\text { alcohol with peroxidase) }\end{array}$ & NA & DHB & $400-2,600 \mathrm{Da}$ & [36] \\
\hline+ & TOF & $\begin{array}{l}\text { Pyrolytic lignin and its SEC } \\
\text { fractions }\end{array}$ & NA & DHB or no matrix & $\begin{array}{l}50-4,000 \mathrm{Da} \\
\text { (unresolved) }\end{array}$ & [40] \\
\hline NA & TOF & $\begin{array}{l}\text { Soda hardwood lignin (Eucalyptus) } \\
\text { and softwood kraft lignin }\end{array}$ & NA & DHB & $70-700 \mathrm{Da}$ & [59] \\
\hline+ & TOF & $\begin{array}{l}\text { Native and degraded birch wood } \\
\text { lignin }\end{array}$ & NA & DHB & $1,000-2,000 \mathrm{~m} / \mathrm{z}$ & [37] \\
\hline
\end{tabular}


${ }^{c}$ DHB stands for 2,5-dihydroxybenzoic acid

${ }^{\text {d }}$ CHCA stands for $\alpha$-cyano-4-hydroxycinnamic acid 


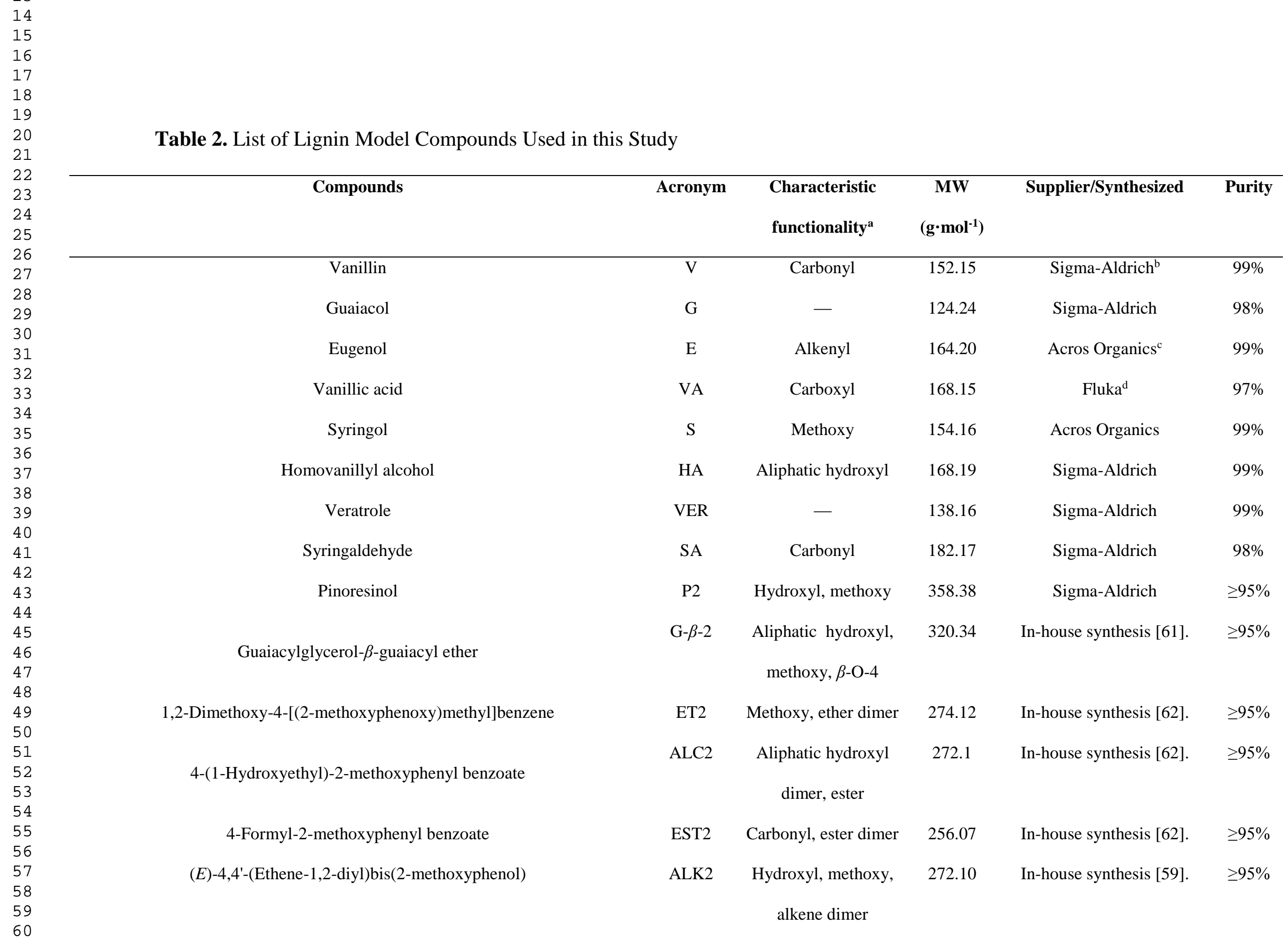


${ }^{a}$ Functional groups and linkages (for oligomers) featured in the studied methoxyphenols compared to guaiacol

${ }^{\mathrm{b}}$ Sigma-Aldrich (St. Louis, MO, USA)

${ }^{c}$ Acros Organics (Morris Plains, NJ, USA)

${ }^{\mathrm{d}}$ Fluka (Steinheim, Germany) 
Table 3. ESI TOF MS Response with Acids (Either Formic or Acetic) and Ammonium Acetate as ESI Electrolytes for Representative Lignin Mono- to Trimeric Structure Model Compounds in Both Positive and Negative Ionization Modes ${ }^{\mathrm{a}}$

\begin{tabular}{|c|c|c|c|c|c|c|c|c|}
\hline \multirow{3}{*}{ Model Compounds } & \multicolumn{4}{|c|}{ Numbers of Oxygenated Functional } & \multicolumn{4}{|c|}{ Intensity of the Target Ion Response } \\
\hline & \multicolumn{3}{|c|}{ Groups } & \multirow[t]{2}{*}{$\mathrm{p} K_{\mathrm{a}}$} & \multicolumn{2}{|c|}{ Acid (Formic/Acetic) } & \multicolumn{2}{|c|}{ Ammonium Acetate } \\
\hline & $-\mathrm{OH}$ & $-\mathrm{OCH}_{3}$ & $-\mathrm{COOH}$ & & Positive & Negative & Positive & Negative \\
\hline VER & $\mathbf{0}$ & 2 & 0 & - & $++++^{\mathrm{b}}$ & $\mathrm{ND}^{\mathrm{c}}$ & +++ & ND \\
\hline EST2 & $\mathbf{0}$ & 1 & 0 & - & ++++ & ND & ++++ & ND \\
\hline ET2 & $\mathbf{0}$ & 3 & 0 & - & ++++ & ND & +++ & ND \\
\hline ET3-1 & $\mathbf{0}$ & 5 & 0 & - & ++++ & ND & +++ & ND \\
\hline ET3-2 & 1 & 5 & 0 & - & ++++ & + & +++ & + \\
\hline $\mathrm{P} 2$ & 2 & 2 & 0 & 9.76 & ++++ & + & +++ & + \\
\hline G- $\beta-2$ & $\begin{array}{c}1 \\
+\mathbf{2} \text { aliphatic }\end{array}$ & 2 & 0 & 9.88 & ++++ & + & +++ & + \\
\hline HA & $\begin{array}{c}1 \\
+\mathbf{1} \text { aliphatic }\end{array}$ & 1 & 0 & 10.19 & +++ & + & ++++ & ++ \\
\hline ALC2 & 1 aliphatic & 1 & 0 & & +++ & + & ++++ & ++ \\
\hline$S$ & 1 & 2 & 0 & 9.98 & ++ & +++ & ++++ & + \\
\hline SA & 1 & 2 & 0 & 7.8 & +++ & + & ++++ & ++ \\
\hline VA & 1 & 1 & 1 & 4.45 & ++ & +++ & + & ++++ \\
\hline V & 1 & 1 & 0 & 7.38 & + & +++ & ++ & ++++ \\
\hline $\mathrm{D} 2 \mathrm{~V}$ & 2 & 2 & 0 & 7.04 & ++ & +++ & + & ++++ \\
\hline $\mathrm{G}$ & 1 & 1 & 0 & 9.93 & ++ & +++ & + & ++++ \\
\hline E & 1 & 1 & 0 & 10.19 & + & ++++ & + & ++++ \\
\hline
\end{tabular}

${ }^{a}$ For the majority of analytes, the response was monitored for $[\mathrm{M}+\mathrm{Na}]^{+}$and $[\mathrm{M}-\mathrm{H}]^{-}$ions in the positive and negative ionization modes, respectively. The electrolyte concentration upon direct infusion was $2.5 \mathrm{mmol} \cdot \mathrm{L}^{-1}$ 
b “++++" indicates the system resulting in the most efficient ionization; "+" indicates the system with the least efficient ionization

c "ND" denotes no molecular ions or adducts were detected

12

13

14

15

16

17

18

19

20

21

22

23

24

25

26

27

28

29

30

31

32

33

34

35

36

37

38

39

40

41

42

43

44

45

46

47

48

49

50

51

52

53

54

55

56

57

58

59

60

61

62

63

64

65 
Table 4. Number-Average, Weight-Average and z-Average Molecular Weight of Lignin Determined by ESI HR TOF MS, GPC and MALDI HR TOF MS

\begin{tabular}{cccc}
\hline & ESI HR TOF MS & GPC [11] & MALDI HR TOF MS \\
\hline $\mathrm{M}_{\mathrm{n}}$ & 1,480 & 1,630 & 830 \\
$\mathrm{M}_{\mathrm{w}}$ & 2,520 & 2,740 & 1,250 \\
$\mathrm{M}_{\mathrm{z}}$ & 3,790 & 3,720 & 2,230 \\
\hline
\end{tabular}




\section{List of Figures}

Figure 1. ESI TOF MS response obtained in the presence of different electrolytes via a direct infusion for two representative dimers (a) G- $\beta$-2; (b) ET2 in the positive and negative ionization modes. For most of the electrolytes used, the response for $[\mathrm{M}+\mathrm{Na}]^{+}$and deprotonated molecular ions is shown, except for $\mathrm{LiCl}$ and $\mathrm{LiOH}$ whose application resulted in the formation of $[\mathrm{M}+\mathrm{Li}]^{+}$. The electrolyte concentration was $1.0 \mathrm{mmol} \cdot \mathrm{L}^{-1}$ unless specified otherwise

Figure 2. Positive ESI TOF mass spectra of $5 \mathrm{ppm} \mathrm{G}-\beta-2\left([\mathrm{M}+\mathrm{Na}]^{+} 343.1152 \mathrm{~m} / \mathrm{z}\right)$ in the presence of $1.0 \mathrm{mmol} \cdot \mathrm{L}^{-1}$ of a) ammonium acetate (mass accuracy error $5 \mathrm{ppm}$ ); b) acetic acid (mass accuracy error $7 \mathrm{ppm}$ ); and c) sodium hydroxide (mass accuracy error $6.7 \mathrm{ppm}$ )

Figure 3. The highest mass-to-charge $(\mathrm{m} / \mathrm{z})$ values of the ions detected in the mass spectrum of (a) 15-90 ppm intact alkali lignin and (c) 15 ppm acetylated alkali lignin dissolved in ACNwater 1:1 in the positive and negative ionization modes while using different electrolytes; MW (Da) obtained after spectrum deconvolution of (b) 15-90 ppm intact alkali lignin and (d) $15 \mathrm{ppm}$ acetylated alkali lignin. The electrolyte concentration was $1.0 \mathrm{mmol} \cdot \mathrm{L}^{-1}$ unless specified otherwise

Figure 4. Positive ESI HR TOF mass spectra of an $80 \mathrm{ppm}$ solution of intact lignin in ACNwater (1:1) with $100 \mathrm{mmol} \cdot \mathrm{L}^{-1}$ formic acid: a), c) and e) zoomed and full original mass spectra; $\mathrm{b}$ ), d) and f) zoomed and full mass spectra after deconvolution

Figure 5. LDI (no matrix) HR TOF mass spectrum of alkali lignin. The insert shows a zoomed in part of the spectrum in the range $2800-8000 \mathrm{~m} / \mathrm{z}$

Fig. 6. a) Ion mobility image of a $100 \mathrm{ppm}$ solution of intact lignin in ACN-water (1:1) with $100 \mathrm{mmol} \cdot \mathrm{L}^{-1}$ formic acid, recorded in the positive ESI mode. b) Original and deconvoluted mass 
spectra of a $100 \mathrm{ppm}$ solution of intact lignin in $\mathrm{ACN}$-water (1:1) with $100 \mathrm{mmol} \cdot \mathrm{L}^{-1}$ formic acid recorded in the positive ESI mode. The blank spectrum was subtracted before deconvolution. An accurate deconvolution algorithm is described in equation 1. 
Figure 1
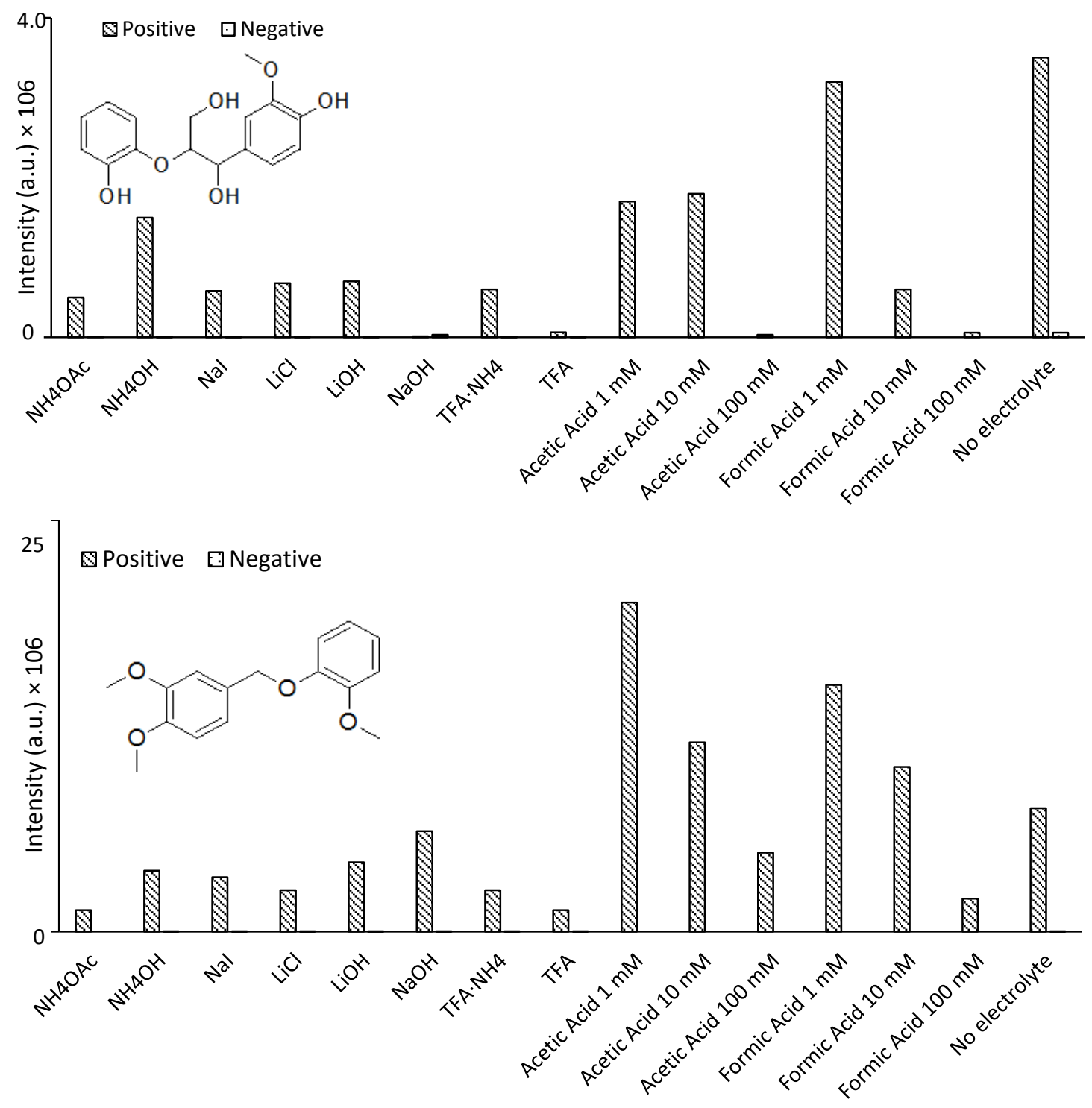
a)

b)

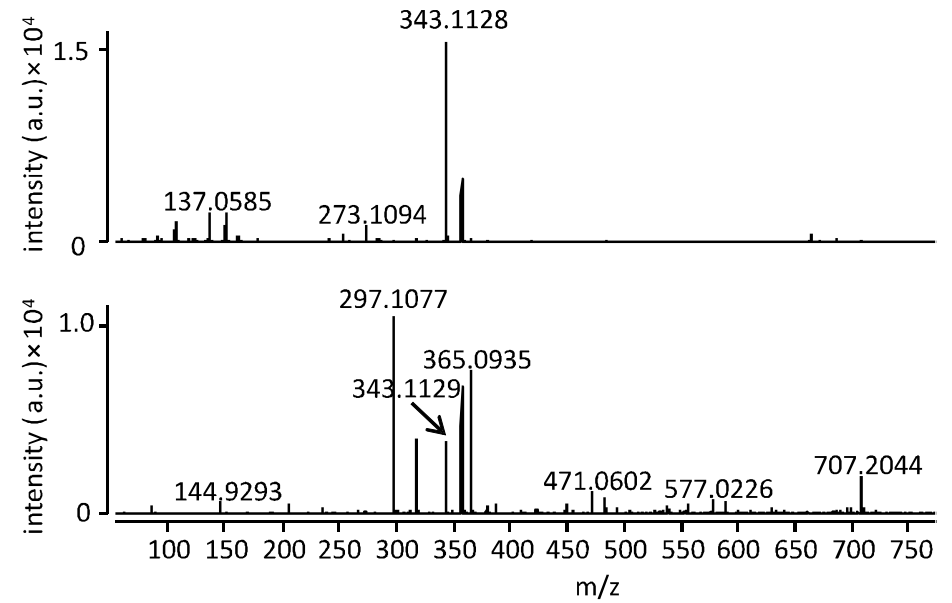
$\mathrm{m} / \mathrm{z}$ 
a)

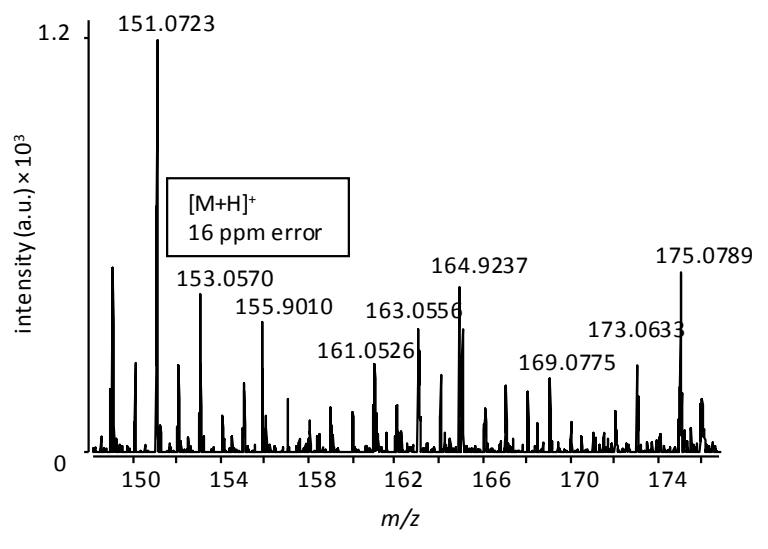

c)

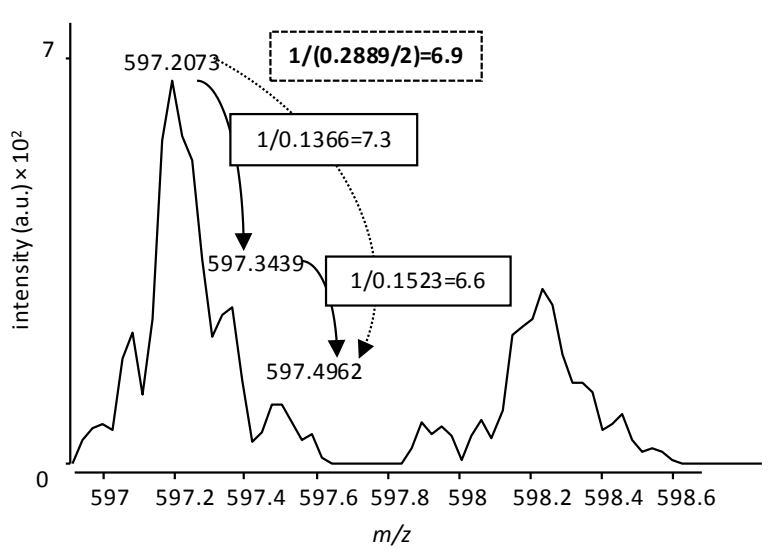

e)

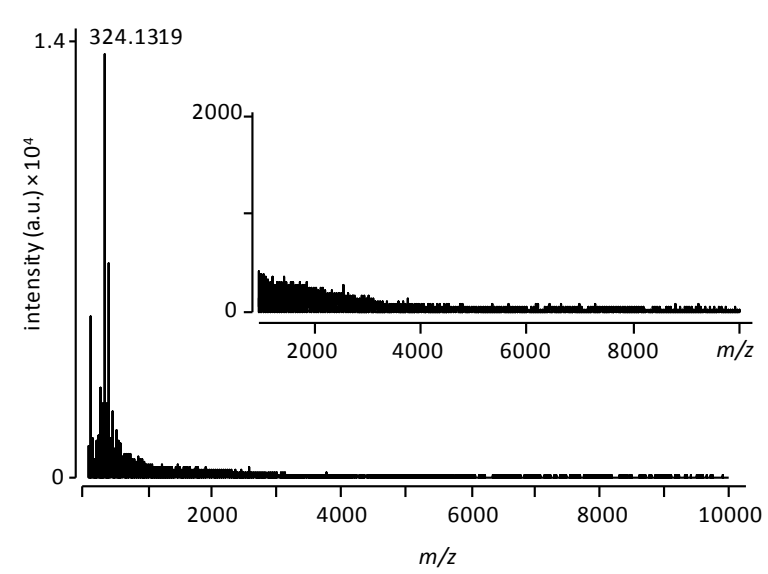

b)

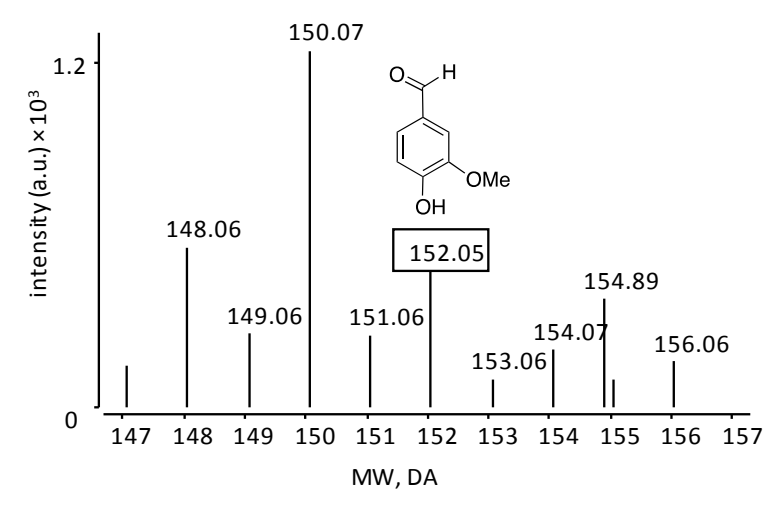

d)

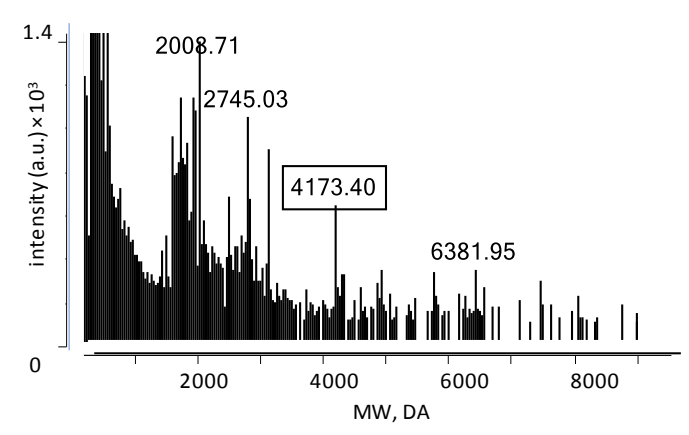

f)

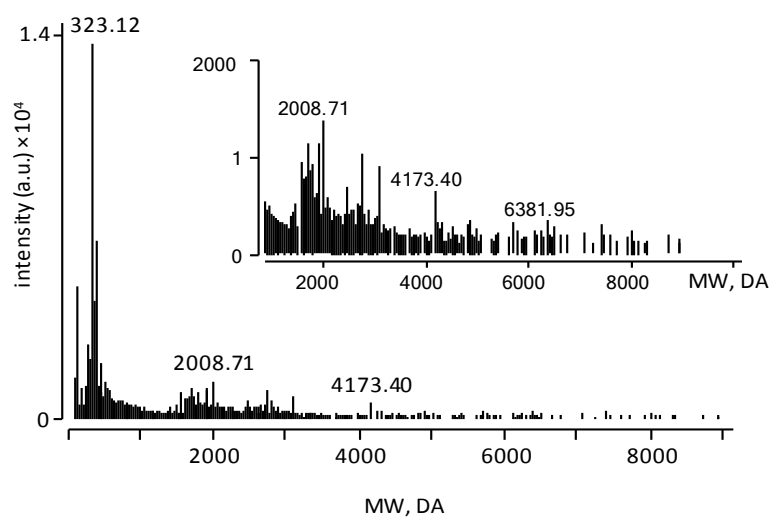




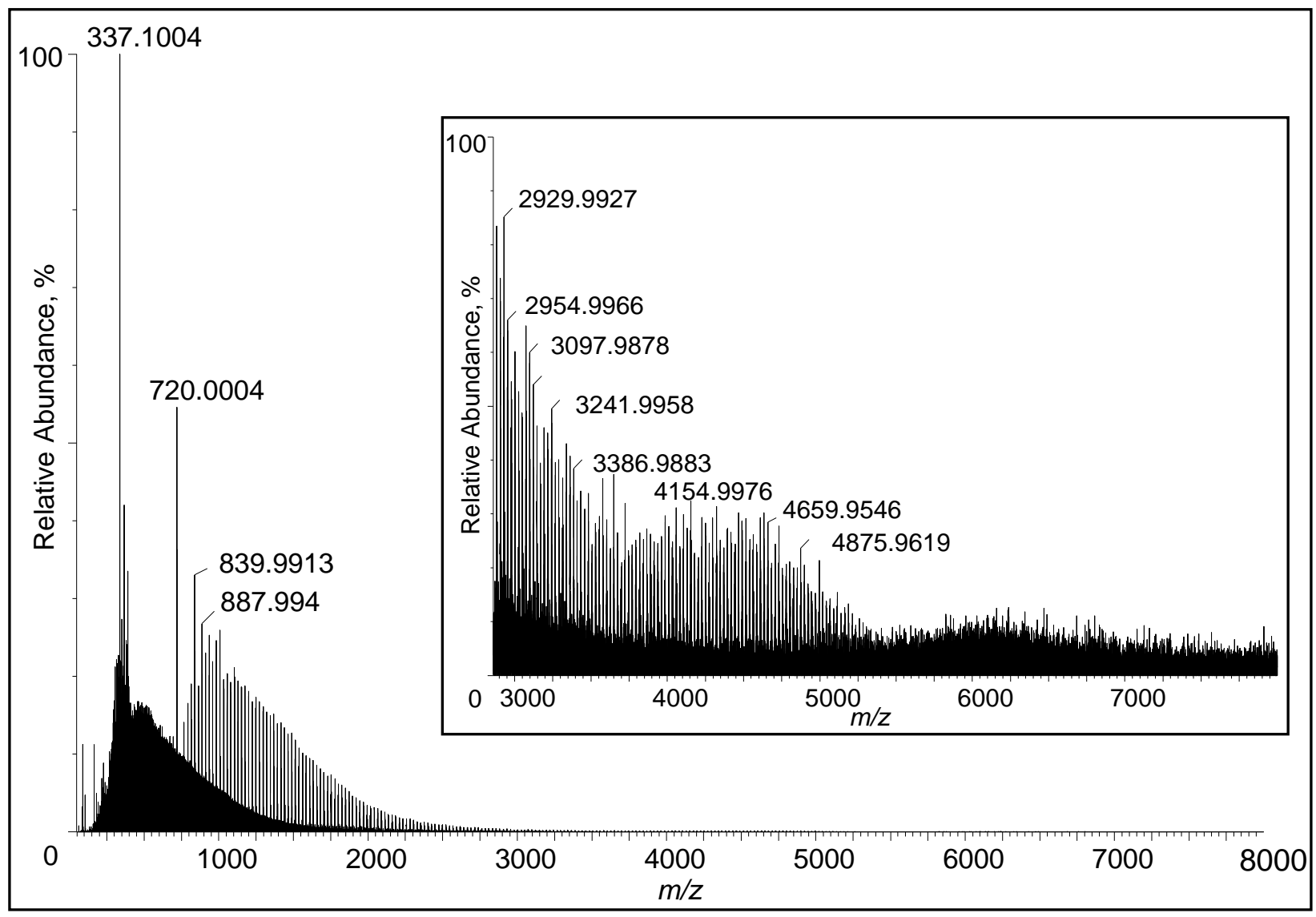


Table 1. Comprehensive Overview of the MS Approaches Employed for the Analysis of Intact Lignin and High MW Standards

\begin{tabular}{|c|c|c|c|c|c|c|}
\hline $\begin{array}{c}\text { Ionization } \\
\text { Mode }\end{array}$ & Mass Analyzer & Analyte & Solvent & $\begin{array}{c}\text { Electrolyte/ } \\
\text { MALDI Matrix }\end{array}$ & $\begin{array}{c}\text { MW or } m / z \\
\text { Range Detected }\end{array}$ & Ref \\
\hline & & & APPI & & & \\
\hline- & Q-orbitrap & Dioxane lignin & $\begin{array}{l}\text { Acetone-water mixture } \\
(9: 1)\end{array}$ & $0.1 \% \mathrm{NH}_{4} \mathrm{OH}$ & $300-1800 \mathrm{~m} / \mathrm{z}$ & {$[47]$} \\
\hline+ & HR Q-TOF-MS & Wheat straw lignin & Dioxane $(100 \%)$ or & $\mathrm{NR}^{\mathrm{a}}$ & Positive mode: & {$[41]$} \\
\hline- & HR Q-TOF-MS & Wheat straw lignin & Dioxane/MeOH/CHCl 3 & & $300-1,120 \mathrm{~m} / \mathrm{z}$ & \\
\hline$+1-$ & HR Q-TOF-MS/MS & Oligomeric species in lignin & $(1: 1: 1)$ & & $\begin{array}{l}\text { Negative mode: } \\
200-700 \mathrm{~m} / \mathrm{z}\end{array}$ & \\
\hline & & & APCI & & & \\
\hline- & Q-orbitrap & Dioxane lignin & $\begin{array}{l}\text { Acetone-water mixture } \\
(9: 1)\end{array}$ & $0.1 \% \mathrm{NH}_{4} \mathrm{OH}$ & $300-1800 \mathrm{~m} / \mathrm{z}$ & [47] \\
\hline- & Ion trap & Synthesized oligomeric standards & $\mathrm{H}_{2} \mathrm{O} / \mathrm{MeOH}(50: 50)$ & $0.1 \%$ acetate & $100-1,000 \mathrm{~m} / \mathrm{z}$ & {$[42]$} \\
\hline- & Single quadrupole & $\begin{array}{l}\text { Lignin partially depolymerized } \\
\text { under acetic conditions }\end{array}$ & $\mathrm{H}_{2} \mathrm{O} / \mathrm{MeOH}$ & NR & $150-650 \mathrm{~m} / \mathrm{z}$ & {$[43]$} \\
\hline$+/-$ & $\begin{array}{l}\text { Quadrupole- } \\
\text { hexapole-- } \\
\text { quadrupole }\end{array}$ & $\begin{array}{l}\text { Wheat straw intact and acetylated } \\
\text { lignin }\end{array}$ & $\mathrm{CHCl}_{3} / \mathrm{MeOH}(2: 1)$ & $\begin{array}{l}\text { A mixture of formic and } \\
\text { acetic acid }\end{array}$ & $100-550 \mathrm{~m} / \mathrm{z}$ & {$[44]$} \\
\hline
\end{tabular}




\begin{tabular}{|c|c|c|c|c|c|c|}
\hline $\begin{array}{c}\text { Ionization } \\
\text { Mode }\end{array}$ & Mass Analyzer & Analyte & Solvent & $\begin{array}{c}\text { Electrolyte/ } \\
\text { MALDI Matrix }\end{array}$ & $\begin{array}{c}\text { MW or } m / z \\
\text { Range Detected }\end{array}$ & Ref \\
\hline \multicolumn{7}{|c|}{ ESI } \\
\hline- & Q-orbitrap & Dioxane lignin & $\begin{array}{l}\text { Acetone-water mixture } \\
(9: 1)\end{array}$ & $0.1 \% \mathrm{NH}_{4} \mathrm{OH}$ & $300-1800 \mathrm{~m} / \mathrm{z}$ & [47] \\
\hline - & Q-TOF & $\begin{array}{l}\text { Dried sorghum feedstock, corn } \\
\text { stover hydrolysate, xylobiose and } \\
\text { xylotetraose }\end{array}$ & $\mathrm{H}_{2} \mathrm{O} /$ traces of $\mathrm{MeOH}$ & None or traces of $\mathrm{H}_{2} \mathrm{SO}_{4}$ & $50-2,000 \mathrm{~m} / \mathrm{z}$ & [51] \\
\hline+ & $\begin{array}{l}\text { Linear trap } \\
\text { quadrupole - } \\
\text { Fourier transform } \\
\text { hybrid linear trap/7- } \\
\text { T Fourier transform } \\
\text { - ion cyclotron } \\
\text { resonance MS }\end{array}$ & $\begin{array}{l}\text { Bagasse lignin }\left(100-100,000 \mathrm{~g} \cdot \mathrm{mol}^{-}\right. \\
{ }^{1} \text { with a maximum at } 2 \cdot 10^{3} \mathrm{~g} \cdot \mathrm{mol}^{-1} \\
\text { according to GPC); } \\
\text { steam explosion lignin }\end{array}$ & DMSO/MeOH (9:1) & NR & $150-2,000 \mathrm{~m} / \mathrm{z}$ & [48] \\
\hline - & Magnetic sector & $\begin{array}{l}\text { Spruce and eucalyptus dioxane } \\
\text { lignin, eucalyptus kraft -organosolv } \\
\text { and oxygen spruce lignin }\end{array}$ & $\begin{array}{l}\mathrm{MeOH} / \mathrm{H}_{2} \mathrm{O}(1: 1) / 2.5 \% \\
\mathrm{NH}_{3} \text { or dioxane } / \mathrm{H}_{2} \mathrm{O} \\
(7: 3)\end{array}$ & $2.5 \% \mathrm{NH}_{4} \mathrm{OH}^{\mathrm{b}}$ & $\begin{array}{l}100-7,000 \mathrm{~m} / z \\
\text { (unresolved at } \\
\text { higher } \mathrm{m} / \mathrm{z} \text { ) }\end{array}$ & [38] \\
\hline- & Q-TOF & $\begin{array}{l}\text { Low-molecular-weight fraction of } \\
\text { E. globulus dioxane lignin }\end{array}$ & $\begin{array}{l}\mathrm{MeOH} / \mathrm{H}_{2} \mathrm{O} \\
(1: 1) / 0.25 \% \mathrm{NH}_{3}\end{array}$ & $0.25 \% \mathrm{NH}_{4} \mathrm{OH}^{\mathrm{b}}$ & $50-1,500 \mathrm{~m} / \mathrm{z}$ & [49] \\
\hline
\end{tabular}




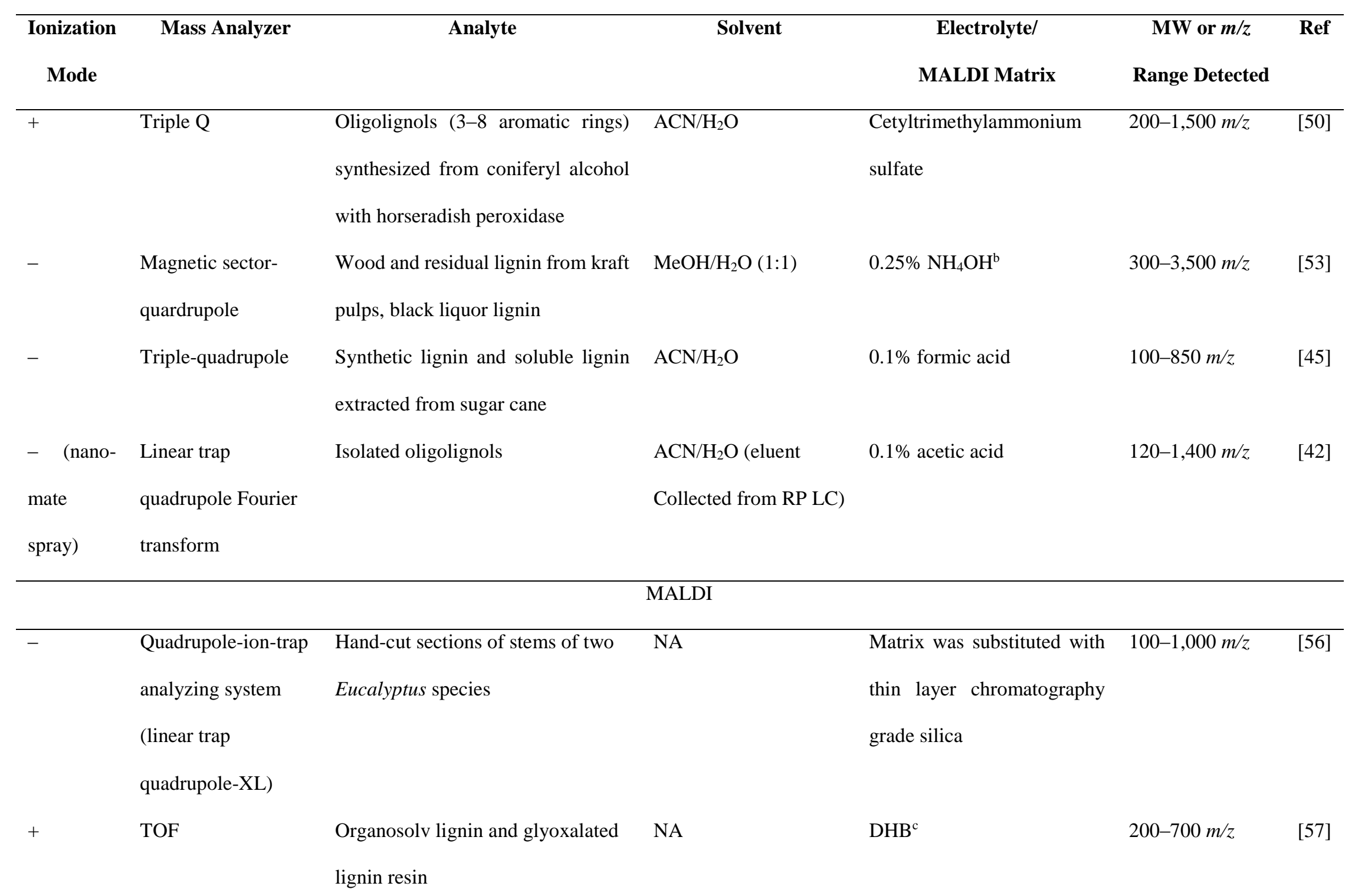




\begin{tabular}{|c|c|c|c|c|c|c|}
\hline $\begin{array}{c}\text { Ionization } \\
\text { Mode }\end{array}$ & Mass Analyzer & Analyte & Solvent & $\begin{array}{c}\text { Electrolyte/ } \\
\text { MALDI Matrix }\end{array}$ & $\begin{array}{c}\text { MW or } m / z \\
\text { Range Detected }\end{array}$ & Ref \\
\hline+ & TOF & $\begin{array}{l}\text { Bagasse lignin }\left(100-100,000 \mathrm{~g} \cdot \mathrm{mol}^{-}\right. \\
{ }^{1} \text { with a maximum at } 2 \cdot 10^{3} \mathrm{~g} \cdot \mathrm{mol}^{-1} \\
\text { according to GPC); } \\
\text { steam explosion lignin }\end{array}$ & NA & DHB & $\begin{array}{l}\text { Mass distribution } \\
\text { with a maximum } \\
\text { around } m / z 360 \text {; } \\
\text { no signal above } \\
2000 \mathrm{~m} / \mathrm{z}\end{array}$ & [48] \\
\hline$+/-$ & TOF & $\begin{array}{l}\text { Lignin fractions extracted from } \\
\text { Miscanthus } x \text { giganteus under } \\
\text { alkali or acid conditions }\end{array}$ & NA & $\mathrm{CHCA}^{\mathrm{d} / \alpha \text {-cyclodextrin }}$ & $100-800 \mathrm{Da}$ & {$[35]$} \\
\hline$+1-$ & TOF & $\begin{array}{l}\text { Ssoftwood kraft lignin, mixed } \\
\text { hardwood organosolv lignin, acid } \\
\text { hydrolysis lignin from bagasse, and } \\
\text { steam explosion lignin from aspen } \\
\text { (acetylated sample) }\end{array}$ & $\mathrm{NA}$ & $\begin{array}{l}\text { DHB or all-trans-retinoic } \\
\text { acid }\end{array}$ & $\begin{array}{l}50-14,000 \mathrm{~m} / \mathrm{z} \\
\text { (unresolved at } \\
\text { higher } \mathrm{m} / \mathrm{z} \text { ); } 50- \\
14,000 \mathrm{Da} \\
\text { (singly charged } \\
\text { ions are almost } \\
\text { exclusively } \\
\text { generated) }\end{array}$ & [39] \\
\hline+ & TOF & $\begin{array}{l}\text { Milled wood lignin, alkali lignin } \\
\text { and a synthetic lignin (G-type) }\end{array}$ & $\mathrm{NA}$ & $\begin{array}{l}\text { DHB, 2-aminobenzoic acid } \\
\text { or sinapinic acid }\end{array}$ & $200-1,700 \mathrm{Da}$ & {$[58]$} \\
\hline
\end{tabular}




\begin{tabular}{|c|c|c|c|c|c|c|}
\hline $\begin{array}{c}\text { Ionization } \\
\text { Mode }\end{array}$ & Mass Analyzer & Analyte & Solvent & $\begin{array}{c}\text { Electrolyte/ } \\
\text { MALDI Matrix }\end{array}$ & $\begin{array}{c}\text { MW or } m / z \\
\text { Range Detected }\end{array}$ & Ref \\
\hline & & $\begin{array}{l}\text { obtained by enzymic } \\
\text { polymerization of coniferyl alcohol }\end{array}$ & & $\begin{array}{lll}\text { (Sinapinic acid } & \text { was } \\
\text { preferred.) } & & \end{array}$ & & \\
\hline$+/-$ & $\begin{array}{l}\text { Quadrupole ion trap } \\
\text { TOF (QIT-TOF) }\end{array}$ & Dioxane lignin & NA & $\begin{array}{l}N \text {-tert-butyl- } N \text {-isopropyl- } N \text { - } \\
\text { methylammonium } \alpha \text {-cyano- } \\
\text { 4-hydroxycinnamate ionic } \\
\text { liquid or no matrix. The } \\
\text { latter provided poor spectral } \\
\text { data. }\end{array}$ & $\begin{array}{l}50-2,000 \mathrm{Da} \\
\text { (unresolved) and } \\
2000-6000 \mathrm{Da} \\
\text { (unresolved) }\end{array}$ & [34] \\
\hline+ & TOF & $\begin{array}{l}\text { Milled wood lignin and synthetic } \\
\text { lignin (polymerisation of coniferyl } \\
\text { alcohol with peroxidase) }\end{array}$ & NA & DHB & $400-2,600 \mathrm{Da}$ & [36] \\
\hline+ & TOF & $\begin{array}{l}\text { Pyrolytic lignin and its SEC } \\
\text { fractions }\end{array}$ & NA & DHB or no matrix & $\begin{array}{l}50-4,000 \mathrm{Da} \\
\text { (unresolved) }\end{array}$ & [40] \\
\hline $\mathrm{NA}$ & TOF & $\begin{array}{l}\text { Soda hardwood lignin (Eucalyptus) } \\
\text { and softwood kraft lignin }\end{array}$ & NA & DHB & $70-700 \mathrm{Da}$ & [59] \\
\hline+ & TOF & $\begin{array}{l}\text { Native and degraded birch wood } \\
\text { lignin }\end{array}$ & NA & DHB & $1,000-2,000 \mathrm{~m} / \mathrm{z}$ & [37] \\
\hline
\end{tabular}




\begin{tabular}{|c|c|c|c|c|c|c|}
\hline $\begin{array}{l}\text { Ionization } \\
\text { Mode }\end{array}$ & Mass Analyzer & Analyte & Solvent & $\begin{array}{c}\text { Electrolyte/ } \\
\text { MALDI Matrix }\end{array}$ & $\begin{array}{c}\text { MW or } m / z \\
\text { Range Detected }\end{array}$ & Ref \\
\hline+ & TOF & $\begin{array}{l}\text { Milled wood lignin, birch kraft } \\
\text { lignin, isolated }\end{array}$ & $\begin{array}{l}\text { DCM/EtOH (2:1) or } \\
\text { DMSO prior to } \\
\text { deposition on silver } \\
\text { disk }\end{array}$ & None & $10-1,200 \mathrm{~m} / \mathrm{z}$ & [60] \\
\hline
\end{tabular}

${ }^{\mathrm{a}} \mathrm{NR}$ denotes not reported

${ }^{\mathrm{b}}$ The w/v concentration was provided in respect to $\mathrm{NH}_{3}$

${ }^{c}$ DHB stands for 2,5-dihydroxybenzoic acid

${ }^{\mathrm{d}}$ CHCA stands for $\alpha$-cyano-4-hydroxycinnamic acid 

Table 2. List of Lignin Model Compounds Used in this Study

\begin{tabular}{|c|c|c|c|c|c|}
\hline Compounds & Acronym & $\begin{array}{l}\text { Characteristic } \\
\text { functionality }^{a}\end{array}$ & $\begin{array}{c}\mathrm{MW} \\
\left(\mathrm{g} \cdot \mathrm{mol}^{-1}\right)\end{array}$ & Supplier/Synthesized & Purity \\
\hline Vanillin & $\mathrm{V}$ & Carbonyl & 152.15 & Sigma-Aldrich $^{b}$ & $99 \%$ \\
\hline Guaiacol & $\mathrm{G}$ & - & 124.24 & Sigma-Aldrich & $98 \%$ \\
\hline Eugenol & $\mathrm{E}$ & Alkenyl & 164.20 & Acros Organics ${ }^{\mathrm{c}}$ & $99 \%$ \\
\hline Vanillic acid & VA & Carboxyl & 168.15 & Fluka $^{\mathrm{d}}$ & $97 \%$ \\
\hline Syringol & $\mathrm{S}$ & Methoxy & 154.16 & Acros Organics & $99 \%$ \\
\hline Homovanillyl alcohol & HA & Aliphatic hydroxyl & 168.19 & Sigma-Aldrich & $99 \%$ \\
\hline Veratrole & VER & - & 138.16 & Sigma-Aldrich & $99 \%$ \\
\hline Syringaldehyde & SA & Carbonyl & 182.17 & Sigma-Aldrich & $98 \%$ \\
\hline \multirow[t]{2}{*}{ Pinoresinol } & $\mathrm{P} 2$ & Hydroxyl, methoxy & 358.38 & Sigma-Aldrich & $\geq 95 \%$ \\
\hline & $\mathrm{G}-\beta-2$ & $\begin{array}{l}\text { Aliphatic hydroxyl, } \\
\text { methoxy, } \beta-\mathrm{O}-4\end{array}$ & 320.34 & In-house synthesis [61]. & $\geq 95 \%$ \\
\hline 1,2-Dimethoxy-4-[(2-methoxyphenoxy)methyl]benzene & ET2 & Methoxy, ether dimer & 274.12 & In-house synthesis [62]. & $\geq 95 \%$ \\
\hline 4-(1-Hydroxyethyl)-2-methoxyphenyl benzoate & ALC2 & $\begin{array}{l}\text { Aliphatic hydroxyl } \\
\text { dimer, ester }\end{array}$ & 272.1 & In-house synthesis [62]. & $\geq 95 \%$ \\
\hline 4-Formyl-2-methoxyphenyl benzoate & EST2 & Carbonyl, ester dimer & 256.07 & In-house synthesis [62]. & $\geq 95 \%$ \\
\hline (E)-4,4'-(Ethene-1,2-diyl)bis(2-methoxyphenol) & ALK2 & $\begin{array}{l}\text { Hydroxyl, methoxy, } \\
\text { alkene dimer }\end{array}$ & 272.10 & In-house synthesis [59]. & $\geq 95 \%$ \\
\hline
\end{tabular}




\begin{tabular}{|c|c|c|c|c|c|}
\hline Dehydrodivanillin & $\mathrm{D} 2 \mathrm{~V}$ & $\begin{array}{l}\text { Carbonyl, hydroxyl, } \\
\text { methoxy, 5-5 dimer }\end{array}$ & 302.07 & In-house synthesis $[63,64]$. & $\geq 95 \%$ \\
\hline 4-[2-(3,4-Dimethoxybenzyl)-4,5-dimethoxybenzyl]-2-methoxyphenol and 1- & ET3-1 & Methoxy, ether trimer & 424.19 & In-house synthesis [62]. & $\geq 95 \%$ \\
\hline (3,4-dimethoxybenzyl)-4,5-dimethoxy-2-[(2-methoxyphenoxy)methyl]benzene & ET3-2 & & & & \\
\hline
\end{tabular}

${ }^{a}$ Functional groups and linkages (for oligomers) featured in the studied methoxyphenols compared to guaiacol

${ }^{\mathrm{b}}$ Sigma-Aldrich (St. Louis, MO, USA)

${ }^{c}$ Acros Organics (Morris Plains, NJ, USA)

${ }^{\mathrm{d}}$ Fluka (Steinheim, Germany) 
Table 3. ESI TOF MS Response with Acids (Either Formic or Acetic) and Ammonium Acetate as ESI Electrolytes for Representative Lignin Mono- to Trimeric Structure Model Compounds in Both Positive and Negative Ionization Modes ${ }^{\mathrm{a}}$

\begin{tabular}{|c|c|c|c|c|c|c|c|c|}
\hline \multirow{3}{*}{ Model Compounds } & \multicolumn{4}{|c|}{ Numbers of Oxygenated Functional } & \multicolumn{4}{|c|}{ Intensity of the Target Ion Response } \\
\hline & \multicolumn{3}{|c|}{ Groups } & \multirow[t]{2}{*}{$\mathrm{p} K_{\mathrm{a}}$} & \multicolumn{2}{|c|}{ Acid (Formic/Acetic) } & \multicolumn{2}{|c|}{ Ammonium Acetate } \\
\hline & $-\mathrm{OH}$ & $-\mathrm{OCH}_{3}$ & $-\mathrm{COOH}$ & & Positive & Negative & Positive & Negative \\
\hline VER & $\mathbf{0}$ & 2 & 0 & - & $++++{ }^{\mathrm{b}}$ & $\mathrm{ND}^{\mathrm{c}}$ & +++ & ND \\
\hline EST2 & $\mathbf{0}$ & 1 & 0 & - & ++++ & ND & ++++ & ND \\
\hline ET2 & $\mathbf{0}$ & 3 & 0 & - & ++++ & ND & +++ & ND \\
\hline ET3-1 & $\mathbf{0}$ & 5 & 0 & - & ++++ & ND & +++ & ND \\
\hline ET3-2 & 1 & 5 & 0 & - & ++++ & + & +++ & + \\
\hline $\mathrm{P} 2$ & 2 & 2 & 0 & 9.76 & ++++ & + & +++ & + \\
\hline G- $\beta-2$ & $\begin{array}{c}1 \\
+\mathbf{2} \text { aliphatic }\end{array}$ & 2 & 0 & 9.88 & ++++ & + & +++ & + \\
\hline HA & $\begin{array}{c}1 \\
+\mathbf{1} \text { aliphatic }\end{array}$ & 1 & 0 & 10.19 & +++ & + & ++++ & ++ \\
\hline ALC2 & 1 aliphatic & 1 & 0 & & +++ & + & ++++ & ++ \\
\hline$S$ & 1 & 2 & 0 & 9.98 & ++ & +++ & ++++ & + \\
\hline SA & 1 & 2 & 0 & 7.8 & +++ & + & ++++ & ++ \\
\hline VA & 1 & 1 & 1 & 4.45 & ++ & +++ & + & ++++ \\
\hline V & 1 & 1 & 0 & 7.38 & + & +++ & ++ & ++++ \\
\hline $\mathrm{D} 2 \mathrm{~V}$ & 2 & 2 & 0 & 7.04 & ++ & +++ & + & ++++ \\
\hline G & 1 & 1 & 0 & 9.93 & ++ & +++ & + & ++++ \\
\hline E & 1 & 1 & 0 & 10.19 & + & ++++ & + & ++++ \\
\hline
\end{tabular}

${ }^{a}$ For the majority of analytes, the response was monitored for $[\mathrm{M}+\mathrm{Na}]^{+}$and $[\mathrm{M}-\mathrm{H}]^{-}$ions in the positive and negative ionization modes, respectively. The electrolyte concentration upon direct infusion was $2.5 \mathrm{mmol} \cdot \mathrm{L}^{-1}$ 
b “++++" indicates the system resulting in the most efficient ionization; "+" indicates the system with the least efficient ionization

c "ND" denotes no molecular ions or adducts were detected 
Table 4. Number-Average, Weight-Average and z-Average Molecular Weight of Lignin Determined by ESI HR TOF MS, GPC and MALDI HR TOF MS

\begin{tabular}{cccc}
\hline & ESI HR TOF MS & GPC [11] & MALDI HR TOF MS \\
\hline $\mathrm{M}_{\mathrm{n}}$ & 1,480 & 1,630 & 830 \\
$\mathrm{M}_{\mathrm{w}}$ & 2,520 & 2,740 & 1,250 \\
$\mathrm{M}_{\mathrm{z}}$ & 3,790 & 3,720 & 2,230 \\
\hline
\end{tabular}


Click here to access/download Supplemental Information Supplementary Material_2017-1026.docx 